\title{
Analysis of a Multiparticipant Game under a Subsidy and Punishment Mechanism: An Evolutionary Theory Perspective
}

\author{
Jiangchao $\mathrm{Li}^{1}$ and Shilei Yang $\mathbb{D}^{2}$ \\ ${ }^{1}$ School of Business Administration, Faculty of Business Administration, Southwestern University of Finance and Economics, \\ Chengdu, Sichuan 610074, China \\ ${ }^{2}$ School of Business Administration, SWUFE-UD Institute of Data Science, Faculty of Business Administration, \\ Southwestern University of Finance and Economics, Chengdu, Sichuan 610074, China \\ Correspondence should be addressed to Shilei Yang; syang@swufe.edu.cn
}

Received 19 May 2021; Revised 29 June 2021; Accepted 12 July 2021; Published 29 July 2021

Academic Editor: Amin Jajarmi

Copyright $\odot 2021$ Jiangchao Li and Shilei Yang. This is an open access article distributed under the Creative Commons Attribution License, which permits unrestricted use, distribution, and reproduction in any medium, provided the original work is properly cited.

\begin{abstract}
In a market with intense competition, cost pressures tempt enterprises to seek profits in ways that infringe on the interests of consumers. This is especially true when market sentiment is weak. In such situations, governments play a vital role in protecting consumers' interests and helping struggling enterprises. We construct a tripartite game model that includes the government, enterprises, and consumers under a subsidy and punishment mechanism. We use this model to investigate the strategic choices made by the participants in an evolutionary game theory (EGT) framework. We present four stable equilibrium points as pure strategy solutions with the aid of a replicator dynamic system. Three main findings are presented in this paper. First, not all equilibrium points can be evolutionary stable strategies (ESSs) when considering the potential motivations of the participants to change strategies. Second, there is an equilibrium point that satisfies the stability condition but changes periodically in its strategy space; strategy changes between participants are not synchronized. Third, the government prefers to subsidize enterprises when enterprise speculation is serious or when enterprise investment in improving production technology is high.
\end{abstract}

\section{Introduction}

With increased competition in the market, many enterprises are adopting various promotional devices such as discounts, rebates, and price-cuts to attract consumers. In some cases, enterprises appear to offer attractive benefits to consumers, but the interests of consumers are compromised by enterprises due to reduced product quality. Aux, a Chinese home appliance brand, is renowned for providing great discounts and low prices to consumers. However, in 2019, it was revealed that there were serious problems in the quality of its air conditioners [1]. It is therefore clear that consumers sometimes gain benefits from enterprises at the expense of the quality of the products that they purchase, and these enterprises obtain extra profits directly from consumers through such speculative behavior.

The Covid-19 pandemic has led to many enterprise bankruptcies around the world, resulting in widespread unemployment. This has reduced consumer income, leading to a decline in consumer purchases and thereby reduced expenditure. Consumers only engage in purchases when there is a strong incentive for them to do so; such incentives can include substantial subsidies or large discounts. The reduction in consumption has resulted in low sales, leaving enterprises mired in serious business problems. Enterprises may then be tempted to induce consumers to purchase their products by using speculative behavior. Haidilao, which provides excellent service and abundant discounts, is popular among consumers in the Chinese catering industry. Although it offers a series of discount items to consumers, the reduction in the size of its dishes and the increase in its products' prices during the pandemic have greatly impaired consumers' interests [2]. Some enterprises that avoid speculative behavior continue to produce products of original quality, albeit at increased production costs due to the strict lockdown policies imposed in response to the 
pandemic. The pandemic will reduce enterprises' profits and imperil the survival of enterprises as they buckle under the pressure of rising production costs and low consumer demand $[3,4]$. In these circumstances, the government plays a vital role in helping enterprises and protecting consumers' interests. On the one hand, the government has a responsibility to restrain enterprises from engaging in speculative behavior that harms the interests of consumers. On the other hand, the government seeks to promote consumption by taking various measures to help enterprises affected by the pandemic to resume normal activities. Given the challenges faced by enterprises and consumers, the government generally uses a set of incentives such as subsidy and supervision policies.

According to statistics from the Chinese Department of Commerce, over 170 cities have various subsidy policies such as issuing vouchers or providing special subsidies [5]. In general, government subsidy programs are beneficial for particular industries such as green manufacturing and agriculture, or for specific populations such as rural residents $[6,7]$. Some cities may choose to subsidize all consumers and thereby help enterprises overcome immediate economic challenges by promoting consumption. Others provide relevant subsidies, such as research and development (R\&D) subsidies, directly to enterprises. Table 1 presents the various measures for some districts in China. Governments also supervise the market behavior of enterprises in an effort to curb speculative conduct $[8,9]$. Consumers' interests are protected by imposing penalties on enterprises that engage in speculative behavior. Consumers can also supervise enterprises by observing, and giving feedback on, the quality of the products that they purchase [10]. A consumer who does not purchase a product cannot provide feedback on the product $[11,12]$. A consumer who purchases a low-quality product acts as a whistleblower, helping the government to recognize the speculative behavior of enterprises to protect the interests of consumers.

We propose a subsidy and punishment mechanism involving three participants: the government, enterprises, and consumers. The mechanism's objective is to promote consumption and constrain the speculative behavior of enterprises. Considering that the government plays a significant role in achieving these objectives, we set up the mechanism from the perspective of the government and analyzed the strategic choices of consumers and enterprises under this subsidy and supervision mechanism. Evolutionary game theory (EGT) is used to better explore the choices of the participants. We seek to find an evolutionarily stable strategy (ESS) in the dynamic game process. The evolutionary paths of multiple participants can also be shown directly, and we can intuitively examine how each participant is affected by different factors in the evolutionary process. If a pure strategy of a participant is irrational, the probability of that pure strategy will be zero in any internal path of dynamic evolution. This implies that the ultimate ESS is a rational result. The evolutionary game is a dynamic adjustment process in a complex system. We include a set of incentives such as subsidies and punishment in this complex dynamic system and observe whether the ultimate strategy can achieve the goal of stimulating consumption and restricting the speculative behavior of enterprises. We use this model to study the conditions that determine the government's choice between subsidizing consumers and subsidizing enterprises. We also study how the three participants select strategies that could drive the dynamic game model to an ESS. We further analyze the factors that are important in limiting enterprises' speculative behavior and promoting consumption. To assess these issues, we use EGT to construct a tripartite dynamic game model that includes the government, enterprises, and consumers. We proceed to analyze the asymptotic stability of the tripartite participants under different conditions. We then discuss the practical feasibility of all of the equilibrium points and examine the evolutionary path of the participants through numerical simulation.

In this article, we conduct the study in the context of multiple participants (i.e., the government, enterprises, and consumers) and incentive combinations (i.e., subsidies and punishments). More importantly, we analyze the real situation of each theoretical ESS in practice, and add the relevant conditions to ensure the existence of theoretical ESS. Furthermore, to avoid an undesirable ESS (i.e., enterprises choose the speculative behavior when the government subsidizes enterprises), we propose a scenario wherein the government may know the probability of the speculative behavior of enterprises. Surprisingly, this scenario does not necessarily avoid the undesirable ESS, even if it could influence other stable strategies.

The rest of the paper is structured as follows. The next section reviews the related literature. Section 3 describes the research questions and proposes the corresponding assumptions among participants. Section 4 establishes the tripartite evolutionary game model and the replicator dynamic system. We also analyze the asymptotic stability of the participants. The detailed proofs of the analytical results are provided in the appendix. Section 5 presents the evolutionary results from a numerical study. Section 6 offers some conclusions.

\section{Literature Review}

Our paper is related to three streams of the literature: the literature on the subsidy and punishment mechanism, the literature on EGT, and the literature on the application of EGT in a subsidy and punishment mechanism.

2.1. Subsidy and Punishment Mechanism. Governments tend to seek to enhance social welfare and promote consumption through a variety of incentives; these include subsidies and penalties. For example, the subsidy program, "Home Appliances in Rural Homes," launched by the Chinese government in 2007, improves the welfare of consumers in rural areas. The program also boosts the domestic market for home appliances, a role that was especially important in the wake of the 2007-2009 economic crisis [7]. Alizamir et al. [6] investigate the impact of consumer and farmer subsidies on social welfare and provide guidelines for subsidy programs 
TABle 1: Subsidy policies in some cities.

\begin{tabular}{lccc}
\hline Subsidy strategy & District & Total subsidy (million CNY) & Government subsidy (million CNY) \\
\hline & Beijing & 12,200 & 2,200 \\
Subsidizing consumers & Hangzhou & 1,180 & 500 \\
& Chengdu & 950 & 200 \\
& Foshan & 600 & 100 \\
\hline Subsidy strategy & District & Maximum subsidy level for an enterprise (million CNY) \\
& Henan & & 4 \\
Subsidizing enterprises & Chongqing & & 10 \\
& Shenzhen & 10 & \\
\hline
\end{tabular}

in the agriculture sector. Edelman et al. [13] point out that sellers who issue discount coupons can attract more new consumers. Nie et al. [14] prove the importance of innovation subsidies for innovative enterprises. In the environmental sector, incentives can be used to ensure that sustainability goals are met. By optimizing the welfare model, Xiao et al. [15] propose two subsidies for electric vehicles in China and explore the optimal purchase and electricity subsidies. Bansal and Gangopadhyay [16] consider various combinations of subsidies and penalties to analyze the effect of different incentive combinations on green manufacturing. Similarly, Sheu and Chen [17] discuss the influence of government financial intervention, that is, green subsidies and green taxation, on green supply chains. The use of the subsidy and penalty mechanism to promote green technologies has attracted growing interest from industry and academia in recent years [18-20].

2.2. Evolutionary Game. A decision-maker struggles to immediately make the best decision in a complex market environment [21]. Many scholars therefore turn to EGT as this framework can produce an ESS in the process of a dynamic game. EGT, a pillar of game theory, was originally applied in biological research by biologists [22]. The concept of an evolutionarily stable equilibrium was first introduced by Smith [23]. The replicator dynamic system was proposed in evolutionary analysis as a tool for solving problems $[23,24]$. These views and methods laid the foundation for the development of evolutionary theory. Significantly, the evolutionary equilibrium strategies among participants are always the results of learning and adjustment rather than one-shot game results; the game allows for errors and allows participants to learn from previous errors to reach stable state strategies $[25,26]$. Thus, EGT is generally used to study the long-term stable strategy choice of participants $[27,28]$.

EGT is well accepted and has fueled academic interest in economics and management [29-31]. Lenox et al. [32] discuss the evolution of the industry in the presence of interdependency between enterprises and contribute to the future development of a company in the industry by strengthening the relationships between both past and future strategies at the firm level and at the industry level. Bunn and Oliveira [33] use evolutionary theory to explore the influence of market interventions on strategy implementation in electricity markets. Chen et al. [34] construct a dynamic system model and analyze the compliance problem of laborers in hospitals through the evolutionary process.

\subsection{Subsidy and Punishment Mechanism in an Evolutionary} Game. In the literature on EGT applications, most research focuses on subsidy and penalty mechanisms, especially in new areas of energy and sustainability. Ji et al. [8] study the diffusion of new energy vehicles and the alleviation of the financial pressure on the government through adopting various measures such as subsidies and punishment. Encarnação et al. [9] shed light on the effect of the subsidy and penalty policy of the government on the adoption of electric vehicles in the long term using an EGT approach. To improve the energy supervision system in China, Yang et al. [10] introduce whistleblowers in their study and examine a tripartite evolutionary game model with regulators and enterprises. They analyze the dynamic trend and stable state of the evolutionary game under subsidy and punishment mechanisms. Zhang et al. [35]adopt an evolutionary theoretical approach to analyze the implementation of the subsidy and penalty policy for sustainable transportation development. For a sustainable supply chain, Mahmoudi and Rasti-Barzoki [36] use an evolutionary game framework to explore the stable strategy of supply chain members under government intervention through an actual case study. Some researchers discuss the application of the subsidy and penalty mechanism to EGT in other sectors. Sun et al. [37] investigate the impact of green investments in the supply chain under a government subsidy mechanism through the EGT approach. Li et al. [38] and Liu et al. [39] analyze the impact of government subsidy policies on innovation objectives in China through system dynamics and EGT approaches.

The above literature review shows that the issue of multiple participants, which is otherwise discussed in the EGT literature, has been overlooked in the literature on incentive combinations. Although some studies focus on various combinations, most of them pay attention to incentive mechanisms with two parties; few studies involve multiple participants. We seek to describe the market environment more completely; we therefore propose a subsidy and double supervision mechanism covering the main actors in the market, that is, the government, enterprises, and consumers. The effectiveness of this mechanism is discussed in the case of multiparty participation. 
In summary, we construct a tripartite game model based on the subsidy and punishment mechanism and analyze relevant problems using an EGT framework. By constantly learning and adjusting, this study gradually approaches satisfactory strategies for the three participants. From the standpoint of the government, we discuss the evolution of the strategies of consumers and enterprises under the subsidy and punishment mechanism. To explore the optimal strategies of the participants, replicator dynamic equations are established through the EGT approach and the possible ESSs are proposed using the Jacobian matrix and stability theory. In this way, we can examine the effectiveness of the incentive mechanism through the result of the ultimate ESS.

\section{Problem Description and Assumptions}

3.1. Problem Description. The evolutionary process is premised on long-term interactions among multiple participants. This paper focuses on three participants, namely, the government, enterprises, and consumers. To mitigate cost pressures caused by the pandemic, enterprises may choose to lower their product quality or improve their production technology. Consumer surplus is higher when consumers purchase normal products-that is, products of higher quality than the low-quality products-than when they purchase low-quality products. Consumer utility is lower with lower-quality products. The government seeks to encourage consumer purchases and prevent enterprises from harming the interests of consumers; to this end, governments generally adopt various policy measures such as subsidies and penalties. The participants in the evolutionary game gradually learn from previous errors and adjust their strategies to maximize their payoffs or the adequacy of their prior step in the game and thus approach the final stable state in a long process. For ease of understanding, we generally use payoffs instead of adequacy in our evolutionary model. We refer the reader to Gu et al. [21], Liu et al. [39], and Encarnação et al. [9] for a comprehensive discussion of payoffs.

3.2. Problem Assumptions. The following assumptions apply to our evolutionary game model involving the three participants. Each participant possesses their own respective strategy space. The strategy space of the government is \{Subsidizing consumers, Subsidizing enterprises\}; this refers to whether the government subsidizes consumers or subsidizes enterprises, respectively. The strategy space $\{$ Speculation, Effort $\}$ indicates that enterprises have two options. The "Effort" strategy is to produce normal products and reduce cost pressures by improving production technology. This strategy requires enterprises to invest more to improve their technology. The "Speculation" strategy entails providing low-quality products. In this case, enterprises will not invest to improve their technology. The consumers' strategy space is \{Purchase, Nonpurchase\}; consumers can choose to buy a product or not, respectively. In this paper, $x, y$, and $z$ represent the probability of the first action of all strategy spaces, $0 \leq x, y, z \leq 1$. Correspondingly, $1-x, 1-y$, and $1-z$ express the probability of the second act of the strategy spaces.

In this study, enterprises provide a product of quality $s_{i}$ to consumers and sell the product at the same retail price $p$. It should be noted that the retail price is already a discounted price to attract consumers. The issue of price discounts is outside the scope of this article. For example, consumers may obtain higher utility from consuming the higher quality product, so their willingness to pay increases, leading to more demand. Hence, the demand for the product is $D=A-\beta p+\gamma s_{i}, A>2 \beta p$. A represents the potential demand in the market, and $\beta$ and $\gamma(\beta>0$ and $\gamma>0)$ indicate the price sensitivity coefficient and the quality sensitivity coefficient, respectively. We assume that the cost of producing a product of quality $s_{i}$ is $\alpha s_{i}^{2}$, where $\alpha>0, s_{i} \geq 1, i=l, h . \alpha$ is the cost coefficient. The quadratic representation of the production cost follows the literature on quality differentiation [40]. When enterprises adopt the "Speculation" strategy to manufacture their products, the quality of the low-quality product is $s_{l}$. In contrast, the quality of the normal product manufactured by the enterprises adopting the "Effort" strategy is higher than the quality of the low-quality product. Hence, the quality of the normal product is $s_{h}$ and $s_{l}<s_{h}\left(s_{l} \in\left[1, s_{h}\right)\right)$. There are two types of investment effort to improve production technology; these are $e_{h}$ and $e_{l}$.

If the government elects to subsidize consumers, it provides each consumer with a voucher. Each voucher can only purchase one product. We assume that $t$ is the face value of the voucher and the total subsidy cost is $t D$ (these subsidy costs are incurred only when consumers buy products). Market demand can therefore be presented as $D_{c}=A-\beta(p-t)+\gamma s_{i}$, with $A>2 \beta(p-t)$ in our model (based on the Willingness To Pay (WTP) model, the consumer utility function satisfies $u=v-p$, where $v$ is the consumer valuation of the product, and $p$ is the price of the product; consumers will only buy the product if $v-p \geq 0$; in this paper, we assume that $v=p$, and $p$ is constant; when the government subsidizes consumers, consumers will buy products when $u=v-p+t \geq 0$; that is, $v=p-t$ ). Enterprises that adopt the "Effort" strategy must pay the corresponding $\mathrm{R} \& \mathrm{D}$ investment $k e_{h}^{2}$. Here, $k$ indicates the $\mathrm{R} \& \mathrm{D}$ coefficient and $e_{h}$ is the effort level chosen by the enterprises, $e_{h}>1$. The unit cost of a normal product is reduced to $\alpha\left(s_{h}^{2} / e_{h}\right)$ after technical improvement $[41,42]$. The unit cost of the low-quality product is still $\alpha s_{l}^{2}$ because speculative enterprises do not invest extra funds to improve their production technology.

When the "Subsidizing enterprises" strategy is selected by the government, enterprises will receive a special subsidy of $k e_{l}^{2}$ from the government to improve their production technology. Here, $e_{l}$ is the effort level that the government subsidizes. In general, the special subsidy provided by the government for $R \& D$ is less than the enterprise's actual investment in R\&D (According to the subsidy implementation measures issued by Shandong Province, China, R\&D investments in enterprises that come from their sales revenue should be greater than the 
subsidy provided by the government for $\mathrm{R} \& \mathrm{D}$. We suppose that the government adopts the effort level $e_{l}$ to subsidize all enterprises when the "Subsidizing enterprises" strategy is selected.). Hence, we suppose that $e_{h}>e_{l}>1$. The effective R\&D investment of enterprises that adopt the "Effort" strategy becomes $k\left(e_{h}^{2}-e_{l}^{2}\right)$ and the unit product cost is still $\alpha\left(s_{h}^{2} / e_{h}\right)$. Speculative enterprises improve their production technology with the aid of the government subsidy $k e_{l}^{2}$, and their unit product cost changes to $\alpha\left(s_{l}^{2} / e_{l}\right)$. Under the strategy of subsidizing enterprises, market demand is $D=D_{e}=A-\beta p+\gamma s_{i}$. As commonly defined in the literature $[34,43,44]$, consumer surplus is the area of the demand curve below a given price, which can be expressed as $D_{c}^{2} / 2$ or $D_{e}^{2} / 2$ in our model.

Enterprises are subject to double supervision from the government and consumers. No matter what strategy the government chooses, supervision of enterprises always happens. $\delta$ is the success probability of government supervision. Consumers who purchase and use the product can also recognize the product type and supervise the behavior of enterprises; the success probability of consumer supervision is $\sigma$. The success probability of supervision is $\theta(\theta=1-(1-$ $\delta)(1-\sigma))$ when enterprises are subject to double supervision. Therefore, fines $\theta\left(F / s_{l}\right)$ (double supervision) and $\delta\left(F / s_{l}\right)$ (single supervision) are imposed on enterprises that sell low-quality products and their speculative behavior is captured by the government or consumers [42]. $F$ represents the maximum penalty and fines decrease with increasing of quality $s_{l}$. The above notations are listed in Table 2 .

In an evolutionary game, the strategy space is information common to the various participants. The three participants make decisions simultaneously, then constantly learn and adjust from the previous stage to reach a stable state in the process of the game. The evolutionary game process diagram is shown in Figure 1.

The government is a nonprofit organization whose objective is to maximize social welfare. Based on the literature $[6,14,45]$, we define social welfare as the sum of penalty income, consumer surplus, and enterprise revenue minus the subsidy cost. The expected profit of enterprises is equal to their revenue minus fines and total costs. See Levi et al. [46] and Yu et al. [47] for detailed descriptions.

The following are the values for each participant in the payoff matrix. The government is denoted by subscript 1 , the enterprise is denoted by subscript 2 , and the consumer is denoted by subscript 3 .

\{Subsidizing consumers, Speculation, Purchase\}

$$
\begin{aligned}
& \amalg_{1}^{\mathrm{CSP}}=\left(A-\beta(p-t)+\gamma s_{l}\right)(p-t)+\frac{\left(A-\beta(p-t)+\gamma s_{l}\right)^{2}}{2}+\theta \frac{F}{s_{l}}, \\
& \amalg_{2}^{\mathrm{CSP}}=\left(A-\beta(p-t)+\gamma s_{l}\right)\left(p-\alpha s_{l}^{2}\right)-\theta \frac{F}{s_{l}}, \\
& \amalg_{3}^{\mathrm{CSP}}=\frac{\left(A-\beta(p-t)+\gamma s_{l}\right)^{2}}{2} .
\end{aligned}
$$

\{Subsidizing consumers, Effort, Purchase\}

$$
\begin{aligned}
& \amalg_{1}^{\mathrm{CEP}}=\left(A-\beta(p-t)+\gamma s_{h}\right)(p-t)+\frac{\left(A-\beta(p-t)+\gamma s_{h}\right)^{2}}{2}-k e_{h}^{2}, \\
& \amalg_{2}^{\mathrm{CEP}}=\left(A-\beta(p-t)+\gamma s_{h}\right)\left(p-\alpha \frac{s_{h}^{2}}{e_{h}}\right)-k e_{h}^{2}, \\
& \amalg_{3}^{\mathrm{CEP}}=\frac{\left(A-\beta(p-t)+\gamma s_{h}\right)^{2}}{2} .
\end{aligned}
$$

\{Subsidizing consumers, Speculation, Nonpurchase\}

$$
\begin{aligned}
& \amalg_{1}^{\mathrm{CSN}}=\delta \frac{F}{s_{l}}, \\
& \amalg_{2}^{\mathrm{CSN}}=-\delta \frac{F}{s_{l}}, \\
& \amalg_{3}^{\mathrm{CSN}}=0 .
\end{aligned}
$$

\{Subsidizing consumers, Effort, Nonpurchase\}

$$
\begin{aligned}
& \amalg_{1}^{\mathrm{CEN}}=-k e_{h}^{2}, \\
& \amalg_{2}^{\mathrm{CEN}}=-k e_{h}^{2} \\
& \amalg_{3}^{\mathrm{CEN}}=0 .
\end{aligned}
$$

\{Subsidizing enterprises, Speculation, Purchase\}

$$
\begin{aligned}
& \amalg_{1}^{\mathrm{ESP}}=\left(A-\beta p+\gamma s_{l}\right) p+\frac{\left(A-\beta p+\gamma s_{l}\right)^{2}}{2}+\theta \frac{F}{s_{l}}-k e_{l}^{2}, \\
& \amalg_{2}^{\mathrm{ESP}}=\left(A-\beta p+\gamma s_{l}\right)\left(p-\alpha \frac{s_{l}^{2}}{e_{l}}\right)-\theta \frac{F}{s_{l}}, \\
& \amalg_{3}^{\mathrm{ESP}}=\frac{\left(A-\beta p+\gamma s_{l}\right)^{2}}{2} .
\end{aligned}
$$

\{Subsidizing enterprises, Effort, Purchase\}

$$
\begin{aligned}
& \amalg_{1}^{\mathrm{EEP}}=\left(A-\beta p+\gamma s_{h}\right) p+\frac{\left(A-\beta p+\gamma s_{h}\right)^{2}}{2}-k e_{l}^{2}, \\
& \amalg_{2}^{\mathrm{EEP}}=\left(A-\beta p+\gamma s_{h}\right)\left(p-\alpha \frac{s_{h}^{2}}{e_{h}}\right)-k\left(e_{h}^{2}-e_{l}^{2}\right), \\
& \amalg_{3}^{\mathrm{EEP}}=\frac{\left(A-\beta p+\gamma s_{h}\right)^{2}}{2} .
\end{aligned}
$$

\{Subsidizing enterprises, Speculation, Nonpurchase\}

$$
\begin{aligned}
& \amalg_{1}^{\mathrm{ESN}}=\delta \frac{F}{s_{l}}-k e_{l}^{2}, \\
& \amalg_{2}^{\mathrm{ESN}}=-\delta \frac{F}{s_{l}}, \\
& \amalg_{3}^{\mathrm{ESN}}=0 .
\end{aligned}
$$

\{Subsidizing enterprises, Effort, Nonpurchase\} 
TABle 2: Notation descriptions.

\begin{tabular}{lcc}
\hline Participants & Notation & Descriptions \\
Government & $t$ & The face value of a voucher \\
& $F$ & The maximum penalty \\
& $\delta$ & The retail price of a product \\
& $P$ & The quality of a product \\
Enterprise & $s_{i}$ & The success probability of double supervision \\
& $e_{i}$ & The effort level of technical improvement \\
& $\gamma$ & The price sensitivity coefficient \\
& $k$ & The quality sensitivity coefficient \\
& $\alpha$ & The R\&D coefficient \\
Consumer & $A$ & The cost coefficient \\
& $\sigma$ & Potential demand \\
& $D$ & The probability that the government chooses to subsidize consumers \\
& $x$ & The probability that enterprises choose to adopt speculative behavior \\
& $y$ & The probability that consumers choose to purchase products \\
\hline
\end{tabular}

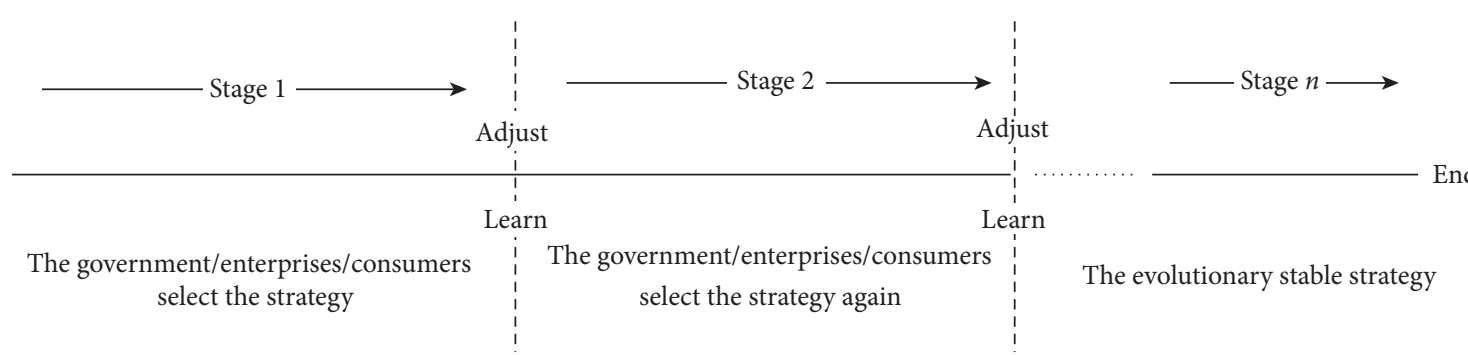

Figure 1: The evolutionary game process diagram.

$$
\begin{aligned}
& \amalg_{1}^{\mathrm{EEN}}=-k e_{l}^{2}, \\
& \amalg_{2}^{\mathrm{EEN}}=-k\left(e_{h}^{2}-e_{l}^{2}\right), \\
& \amalg_{3}^{\mathrm{EEN}}=0 .
\end{aligned}
$$
and assumptions presented above, the payoff matrix of the tripartite evolutionary game is shown in Table 3 .

$U_{G 1}$ and $U_{G 2}$ refer to the expected benefits of subsidizing consumers and subsidizing enterprises for the government, respectively. If $\overline{U_{G}}$ represents the average benefits of the government, then:

\section{Model Solution and Analysis}

4.1. The Replicator Dynamic System. Based on the analysis

$$
\begin{aligned}
U_{G 1} & =y z \amalg_{1}^{\mathrm{CSP}}+(1-y) z \amalg_{1}^{\mathrm{CEP}}+y(1-z) \amalg_{1}^{\mathrm{CSN}}+(1-y)(1-z) \amalg_{1}^{\mathrm{CEN}}, \\
U_{G 2} & =y z \amalg_{1}^{\mathrm{ESP}}+(1-y) z \amalg_{1}^{\mathrm{EEP}}+y(1-z) \amalg_{1}^{\mathrm{ESN}}+(1-y)(1-z) \amalg_{1}^{\mathrm{EEN}}, \\
\overline{U_{G}} & =x U_{G 1}+(1-x) U_{G 2} .
\end{aligned}
$$

The replicator dynamic equation of the government can therefore be expressed as follows:

$$
F(x)=\frac{\mathrm{d} x}{\mathrm{~d} t}=x\left(U_{G 1}-\overline{U_{G}}\right)=x(1-x)\left(U_{G 1}-U_{G 2}\right),
$$

where

$$
\begin{array}{r}
U_{G 1}-U_{G 2}=z\left[t \left(-\beta^{2} p+\beta\left(A+2 p+\gamma\left(s_{h}-y\left(s_{h}-s_{l}\right)\right)\right)\right.\right. \\
\left.\left.+\gamma\left(y\left(s_{h}-s_{l}\right)-s_{h}\right)-A\right)+\frac{\beta t^{2}(\beta-2)}{2}\right]-k\left[e_{h}^{2}(1-y)-e_{l}^{2}\right] .
\end{array}
$$

Similarly, $U_{E 1}$ and $U_{E 2}$ denote the expected benefits of the "Speculation" strategy and the "Effort" strategy for 
TABLE 3: Payoff matrix for the government, enterprises, and consumers.

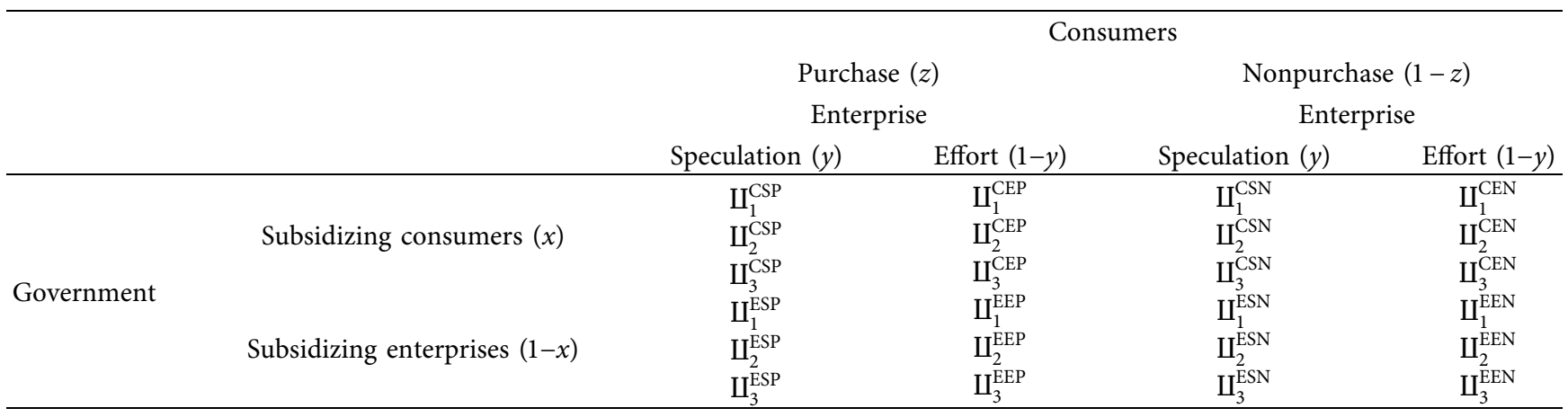

enterprises, respectively. If $\overline{U_{E}}$ is the average benefits of enterprises, then:

$$
\begin{aligned}
U_{E 1} & =x z \amalg_{2}^{\mathrm{CSP}}+(1-x) z \amalg_{2}^{\mathrm{ESP}}+x(1-z) \amalg_{2}^{\mathrm{CSN}}+(1-x)(1-z) \amalg_{2}^{\mathrm{ESN}}, \\
U_{E 2} & =x z \amalg_{2}^{\mathrm{CEP}}+(1-x) z \amalg_{2}^{\mathrm{EEP}}+x(1-z) \amalg_{2}^{\mathrm{CEN}}+(1-x)(1-z) \amalg_{2}^{\mathrm{EEN}}, \\
\overline{U_{E}} & =y U_{E 1}+(1-y) U_{E 2} .
\end{aligned}
$$

The replicator dynamic equation of enterprises can where therefore be written as follows:

$$
F(y)=\frac{\mathrm{d} y}{\mathrm{~d} t}=y\left(U_{E 1}-\overline{U_{E}}\right)=y(1-y)\left(U_{E 1}-U_{E 2}\right),
$$

$$
\begin{aligned}
U_{E 1}-U_{E 2} & =\frac{e_{l} s_{l}\left[k e_{h}^{3}-k e_{h} e_{l}^{2}(1-x)\right]-\delta F e_{h} e_{l}}{e_{h} e_{l} s_{l}}+ \\
& \left.\frac{z\left[-\alpha \gamma e_{h} s_{l}^{4}\left(1-x+x e_{l}\right)-\alpha e_{h} s_{l}^{3}\left(x e_{l}(A-\beta(p-t))+(1-x)(A-\beta p)\right)+\gamma e_{h} e_{l} s_{l}^{2} p+e_{l} s_{l}\left(-\gamma e_{h} s_{h} p+\alpha s_{h}^{2}\left(A-\beta p+\gamma s_{h}+x \beta t\right)\right)-F e_{h} e_{l}(\theta-\delta)\right]}{e_{h} e_{l} s_{l}}\right\} .
\end{aligned}
$$

$U_{C 1}$ and $U_{C 2}$ indicate the expected benefits of the "Purchase" strategy and the "Nonpurchase" strategy for consumers, respectively. If $\overline{U_{C}}$ is the average benefits of consumers, then:

$$
\begin{aligned}
U_{C 1} & =x y \amalg_{3}^{\mathrm{CSP}}+x(1-y) \amalg_{3}^{\mathrm{CEP}}+(1-x) y \amalg_{3}^{\mathrm{ESP}}+(1-x)(1-y) \amalg_{3}^{\mathrm{EEP}}, \\
U_{C 2} & =0, \\
\overline{U_{C}} & =z U_{C 1}+(1-z) U_{C 2} .
\end{aligned}
$$

The replicator dynamics equation of consumers can

$$
F(z)=\frac{\mathrm{d} z}{\mathrm{~d} t}=z\left(U_{C 1}-\overline{U_{C}}\right)=z(1-z)\left(U_{C 1}-U_{C 2}\right),
$$
therefore be denoted as follows: 
where

$$
\begin{aligned}
U_{C 1}-U_{C 2}= & y\left[\frac{\gamma^{2}\left(s_{l}^{2}-s_{h}^{2}\right)}{2}+\gamma\left(s_{l}-s_{h}\right)(A-\beta(p-x t))\right] \\
& +\frac{\gamma^{2} s_{h}^{2}}{2}+\gamma s_{h}(A-\beta(p-x t))+\frac{\beta^{2}\left(p^{2}+x t^{2}-2 x t p\right)}{2}-\beta A(p-x t)+\frac{A^{2}}{2} .
\end{aligned}
$$

According to the explanation given by Freidman [48], the replicator dynamic system is used to describe the strategy selection process of the participants. We can obtain corresponding replicator dynamic equations in the tripartite game from equations (10), (13), and (16).

4.2. Asymptotic Stability Discussion. We further analyze the asymptotic stability of the replicator dynamic system. According to dynamic system stability theory and the requirements of the evolutionary game, the process of strategy adjustment tends toward a stable state if and only if $F(\cdot)=0$ and $F^{\prime}(\cdot)<0$ hold simultaneously. Recall that $x, y$, and $z$ are the probability of the first act of the strategy spaces, and $0 \leq x, y, z \leq 1$.

According to the replication dynamic equation of the government, if $F(x) \equiv 0$, then we have $z^{*}=2 k\left[e_{h}^{2}(1-y)-\right.$ $\left.e_{l}^{2}\right] / t\left[\beta^{2}(t-2 p)+2 \beta\left(\gamma\left((1-y) s_{h}+y s_{l}\right)+A+2 p-t\right)-2 \gamma\right.$ $\left.\left((1-y) s_{h}+y s_{l}\right)-2 A\right]$. To ensure that the assumption $z^{*} \geq 0$ holds, $y>\max \left\{e_{h}^{2}-e_{l}^{2} / e_{h}^{2}, \beta^{2}(2 p-t)-2 \beta\left(\gamma s_{h}+A+\right.\right.$ $\left.2 p-t)+2 \gamma s_{h}+2 A / 2 \gamma(1-\beta)\left(s_{h}-s_{l}\right)\right\} \quad$ When $z>z^{*}$, $\left.F^{\prime}(x)\right|_{x=0}>0$ and $\left.F^{\prime}(x)\right|_{x=1}<0, x=1$ is an ESS; the corresponding dynamic phase diagram is shown in Figure 2(a). Figure 2(b) indicates that if $z<z^{*},\left.F^{\prime}(x)\right|_{x=0}<0$ and $\left.F^{\prime}(x)\right|_{x=1}>0$, then $x=0$ is an ESS. As enterprises increase their investment in technology improvement $\left(e_{h}\right)$, the government is increasingly willing to help them reduce their production costs by directly offering subsidies to improve their technology, as shown in Figure 2(b). This approach by the government can reduce the cost pressures that enterprises face and encourage enterprises to improve their production technology. Figure 2(a) illustrates that as the government subsidy $\left(e_{l}\right)$ for enterprises increases, the higher subsidy costs cause the government to increasingly prefer to subsidize consumers. When the quality of products $\left(s_{l}\right)$ produced by speculative enterprises gradually increases, the government also tends to subsidize consumers by issuing vouchers. Although the improvement in the product quality of speculative enterprises will reduce the penalty income of the government, it will increase consumer demand and consumer surplus. Thus, the result of narrowing the quality gap between low-quality products and normal products is that the government will obtain more social welfare by subsidizing consumers.

Similarly, based on the replication equation of enterprises, if $F(y) \equiv 0$, we have $z^{*}=e_{h} e_{l}\left[k s_{l}\left(e_{h}^{2}-(1-x) e_{l}^{2}\right)-\right.$ $\delta F] / \alpha \gamma e_{h} s_{l}^{4}\left(1-x+x e_{l}\right)+\alpha\left[x e_{l}(A-\beta(p-t))+e_{h} s_{l}^{2}(1-\right.$ $x)(A-\beta p)]-\gamma e_{h} e_{l} p s_{l}^{2}-s_{h} s_{l} p\left[\alpha s_{h}\left(A-\beta p+\gamma s_{h}+x \beta t\right)\right.$ $\left.-\gamma e_{h} p\right]+F e_{h} e_{l}(\theta-\delta)$. To ensure that the above equation satisfies the assumption, $x>\max \left\{\delta F-k s_{l}\left(e_{h}^{2}-e_{l}^{2}\right) / k s_{l} e_{l}^{2}\right.$, $\gamma e_{h} e_{l} p s_{l}^{2}+s_{h} s_{l} p\left[\alpha s_{h}\left(A-\beta p+\gamma s_{h}\right)-\gamma e_{h} p\right]-\alpha e_{h} s_{l}^{3} \quad(A-\beta$ $p)-\alpha \gamma e_{h} s_{l}^{4}-F e_{h} e_{l}(\theta-\delta) / \alpha s_{l}\left[e_{h} e_{l} s_{l}^{3}\left(e_{l}-1\right)+\quad e_{h} s_{l}^{2}\left(e_{l}\right.\right.$ $\left.\left.(A-(p-t)-A+\beta p)-\beta t e_{l} s_{l}^{2}\right]\right\}$. Figure 3(a) shows that if $z<z^{*},\left.F^{\prime}(y)\right|_{y=0}>0$ and $\left.F^{\prime}(y)\right|_{y=1}<0$, then $y=1$ is an ESS. If $z>z^{*},\left.F^{\prime}(y)\right|_{y=0}<0$ and $\left.F^{\prime}(y)\right|_{y=1}>0$, then $y=0$ is an ESS; the phase diagram is shown in Figure 3(b). Intuitively, whatever the type of supervision $(\theta$ or $\delta$ ) reinforced, supervision can urge enterprises to adopt the "Effort" strategy (drive $y$ toward 0 ), as shown in Figure 3(b). A supervision mechanism can effectively curb enterprises' speculative behavior because enterprises caught in such behavior will face fines. To clearly determine the impact of the effort levels $\left(e_{h}\right.$ and $\left.e_{l}\right)$, we discuss this problem through numerical analysis.

For consumers, let $F(z) \equiv 0$, then $y^{*}=\beta^{2}\left(p^{2}+x t^{2}-\right.$ $2 x t p)-2 \beta\left(A+\gamma s_{h}\right)(p-x t)+\left(A+\gamma s_{h}\right)^{2} / \gamma\left(s_{h}-s_{l}\right)\left[\gamma\left(s_{h}+\right.\right.$ $\left.\left.s_{l}\right)+2(A-\beta p+x \beta t)\right]$.

To ensure that $y^{*} \geq 0, \quad x>\max -A^{2}+\gamma^{2} s_{h}^{2}+\beta^{2} p^{2}+$ $2\left(\gamma A s_{h}-\beta A p-\gamma \beta p s_{h}\right) / \beta t\left[2\left(\gamma s_{h}-\beta p+A\right)+\beta t\right],-2 A-2$ $\left.\beta p+\gamma\left(s_{h}+s_{l}\right) / 2 \beta t\right\}$. When $y<y^{*},\left.\quad F^{\prime}(z)\right|_{z=0}>0$ and $\left.F^{\prime}(z)\right|_{z=1}>0, z=1$ is an ESS, as shown in Figure 4(a). When $y>y^{*},\left.F^{\prime}(z)\right|_{z=0}<0$ and $\left.F^{\prime}(z)\right|_{z=1}>0, z=0$ is an ESS, as shown in Figure 4(b). From the analysis, we can observe that the increase in the product quality of speculative enterprises $\left(s_{l}\right)$ and the government subsidy $(t)$ will prompt consumers to make a purchase decision ( $z$ moves toward 1$)$. As noted in the introduction, consumers are more willing to make purchase decisions when they are motivated by external stimuli.

From the above discussion, we know that each participant's strategy is correlated with that of the other two participants; each participant considers the strategies chosen by the other participants and adjusts and decides its strategy in this complex system. In the next subsection, we consider the perspective of the tripartite participants and further explore the evolving stable conditions between the three participants.

4.3. Evolutionary Stable Strategy Analysis. To seek the ESS of the tripartite game, let the equations of the government, enterprises, and consumers in the replicator dynamic system be 0 . That is, $F(x)=F(y)=F(z)=0$. According to the previous analysis and assumptions, we could obtain all equilibrium points of the tripartite evolutionary game in the solution domain $\Omega$, that is, $\Omega=\{x, y, z \mid 0 \leq x \leq 1,0 \leq y \leq 1,0 \leq z \leq 1\}$. In accordance with the condition that the ESS must be a strict pure Nash Equilibrium [48], only eight special equilibrium points for pure strategy solutions need be discussed. These are $E_{1}(0,0,0), E_{2}(1,0,0), E_{3}(0,1,0), E_{4}(0,0,1), E_{5}(1$, 


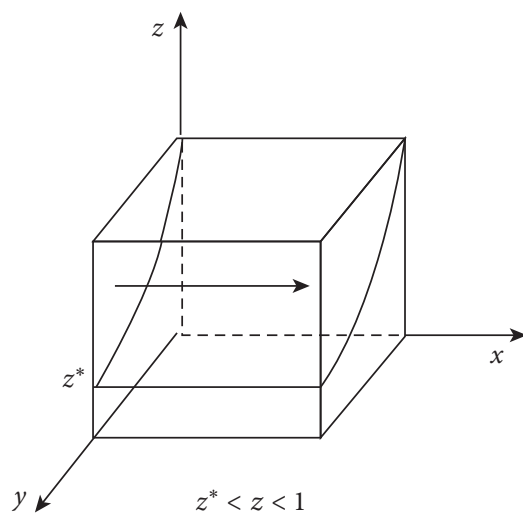

(a)

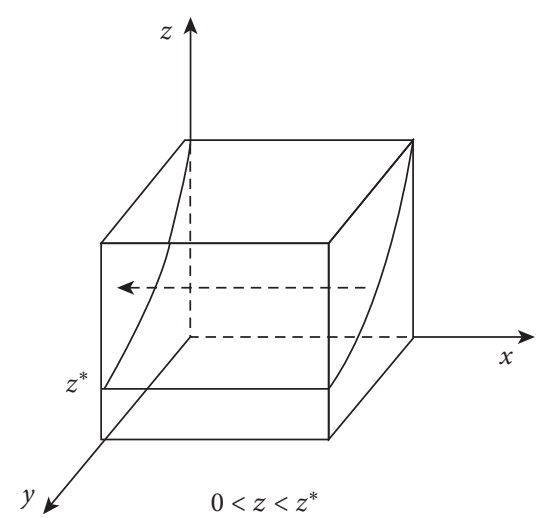

(b)

FIGURE 2: The phase diagrams of the government.

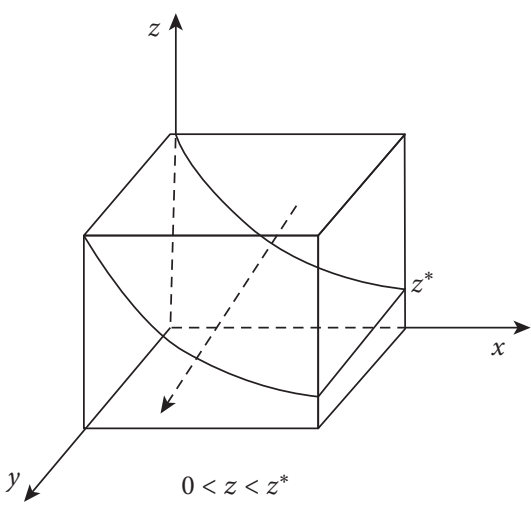

(a)

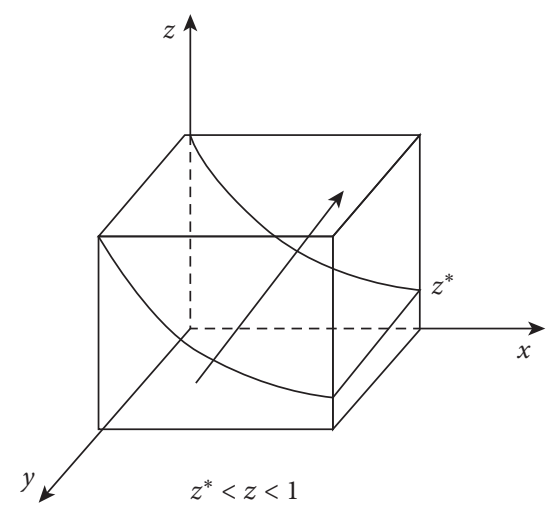

(b)

FIgURE 3: The phase diagrams of enterprises.

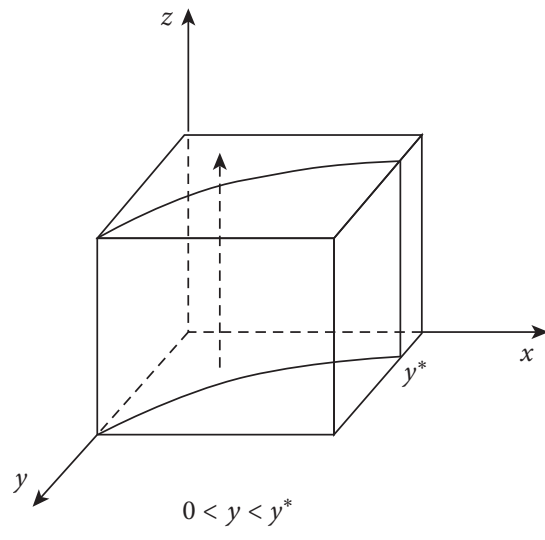

(a)

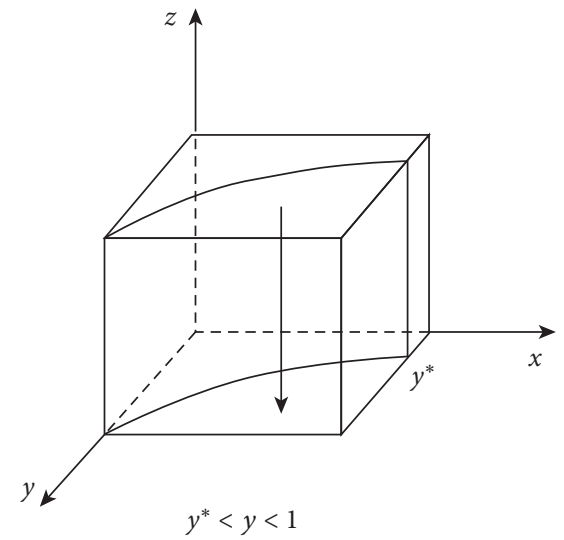

(b)

Figure 4: The phase diagrams of consumers.

$1,0), E_{6}(1,0,1), E_{7}(0,1,1)$, and $E_{8}(1,1,1)$. Besides, there are seven internal equilibrium points for the tripartite evolutionary game, as well as these internal equilibrium in this study are provided in the Appendix.
To assess which of these equilibrium points are ESSs, we need to examine the stability of each equilibrium point. Based on the method introduced by Freidman [48], we seek the evolutionary stable state of the tripartite dynamic system 
through the Jacobian matrix. The Jacobian matrix of our model is as follows:

$$
J=\left[\begin{array}{lll}
F_{11} & F_{12} & F_{13} \\
F_{21} & F_{22} & F_{23} \\
F_{31} & F_{32} & F_{33}
\end{array}\right]=\left[\begin{array}{lll}
\frac{\mathrm{d} F(x)}{\mathrm{d} x} & \frac{\mathrm{d} F(x)}{\mathrm{d} y} & \frac{\mathrm{d} F(x)}{\mathrm{d} z} \\
\frac{\mathrm{d} F(y)}{\mathrm{d} x} & \frac{\mathrm{d} F(y)}{\mathrm{d} y} & \frac{\mathrm{d} F(y)}{\mathrm{d} z} \\
\frac{\mathrm{d} F(z)}{\mathrm{d} x} & \frac{\mathrm{d} F(z)}{\mathrm{d} y} & \frac{\mathrm{d} F(z)}{\mathrm{d} z}
\end{array}\right] .
$$

According to the previous analysis, $F_{11}=F^{\prime}(x)=$ $\mathrm{d} F(x) / \mathrm{d} x, \quad F_{22}=F^{\prime}(y)=\mathrm{d} F(y) / \mathrm{d} y, \quad$ and $\quad F_{33}=F^{\prime}(z)=$ $\mathrm{d} F(z) / \mathrm{d} z$. We can analyze the stability of the equilibrium point using eigenvalues. The eigenvalues of the Jacobian matrix at the corresponding equilibrium conditions are shown in Table 4.

Lyapunov stability theory [49] that applies to a linear system and a nonlinear system is used to analyze the stability of this evolutionary game model. This method is used to investigate the eigenvalues of the eight equilibrium points in this study. The analysis indicates that we could obtain two feasible solutions:

4.3.1. There Are Four Equilibrium Points for Pure Strategy Solutions in the Tripartite Game. Based on Lyapunov's indirect method, the system stability at certain equilibrium points can be measured, as in Table 4 . If the eigenvalues of the equilibrium points are all negative, the equilibrium point is stable (or is called a confluence). If the eigenvalues of the equilibrium points are all positive, the equilibrium point is unstable (or is called a source). When some eigenvalues are negative and others are positive, the equilibrium point is also unstable and is referred to as a saddle point. The equilibrium point is therefore unstable when there exists at least one positive number in the eigenvalues. Recall that all parameters in Table 1 are positive. Considering the above eigenvalues, we believe that the equilibrium points $(0,0,1),(1,0$, $1),(0,1,1)$, and $(1,1,1)$ may be ESSs.

If \{Subsidizing enterprises, Effort, Purchase\}, that is, $(0$, $0,1)$, is an ESS, then:

$$
\begin{aligned}
& k e_{l}^{2}<k e_{h}^{2}+t(1-\beta)\left(A-\beta p+\gamma s_{h}\right)-\beta t\left(p-t+\frac{\beta t}{2}\right), \\
& k\left(e_{h}^{2}-e_{l}^{2}\right)+\alpha \frac{s_{h}^{2}}{e_{h}}\left(A-\beta p+\gamma s_{h}\right)-\alpha \frac{s_{l}^{2}}{e_{l}}\left(A-\beta p+\gamma s_{l}\right)-\theta \frac{F}{s_{l}}<p \gamma\left(s_{h}-s_{l}\right) .
\end{aligned}
$$

The government restricts the speculative behavior of enterprises by subsidizing them; quality guaranteed products in the market will also boost consumer confidence in purchasing.
If $\{$ Subsidizing consumers, Effort, Purchase $\}$, that is, $(1,0$, 1) is an ESS, then:

$$
\begin{aligned}
& k e_{l}^{2}>k e_{h}^{2}+t(1-\beta)\left(A-\beta p+\gamma s_{h}\right)-\beta t\left(p-t+\frac{\beta t}{2}\right), \\
& k e_{h}^{2}+\alpha \frac{s_{h}^{2}}{e_{h}}\left(A-\beta(p-t)+\gamma s_{h}\right)-\alpha \frac{s_{l}^{2}}{e_{l}}\left(A-\beta(p-t)+\gamma s_{l}\right)-\theta \frac{F}{s_{l}}<p \gamma\left(s_{h}-s_{l}\right) .
\end{aligned}
$$

Enterprises can also adopt the "Effort" strategy to provide consumers with normal quality products when the government subsidizes consumers by issuing a voucher. From the perspective of the government, whatever strategy the government chooses, enterprises are likely to choose the "Effort" strategy.

If \{Subsidizing consumers, Speculation, Purchase $\}$, that is, $(1,1,1)$, is an ESS, then:

$$
\begin{aligned}
& k e_{l}^{2}>t(1-\beta)\left(A-\beta p+\gamma s_{l}\right)-\beta t\left(p-t+\frac{\beta t}{2}\right), \\
& k e_{h}^{2}+\alpha \frac{s_{h}^{2}}{e_{h}}\left(A-\beta(p-t)+\gamma s_{h}\right)-\alpha \frac{s_{l}^{2}}{e_{l}}\left(A-\beta(p-t)+\gamma s_{l}\right)-\theta \frac{F}{s_{l}}>p \gamma\left(s_{h}-s_{l}\right) .
\end{aligned}
$$


TABLE 4: Stability analysis results.

\begin{tabular}{lcccc}
\hline Equilibrium point & & & Eigenvalues \\
& $\lambda_{1}$ & $\lambda_{2}$ & $\lambda_{3}$ & Stability \\
\hline$E_{1}=(0,0,0)$ & - & + or - & + & Unstable \\
$E_{2}=(1,0,0)$ & + & + or - & + & Unstable/saddle point \\
$E_{3}=(0,1,0)$ & + & + or - & + & Unstable/saddle point \\
$E_{4}=(0,0,1)$ & + or - & + or - or & - & Stable/saddle point \\
$E_{5}=(1,1,0)$ & - & + or - & - & Unstable \\
$E_{6}=(1,0,1)$ & + or - & + or - & - & Stable/saddle point \\
$E_{7}=(0,1,1)$ & + or - & + or - & - & Stable/saddle point \\
$E_{8}=(1,1,1)$ & + or - & & Stable/saddle point \\
\hline
\end{tabular}

Likewise, if \{Subsidizing enterprises, Speculation, Purchase $\}$, that is, $(0,1,1)$ is an ESS, then:

$$
\begin{aligned}
& k e_{l}^{2}<t(1-\beta)\left(A-\beta p+\gamma s_{l}\right)-\beta t\left(p-t+\frac{\beta t}{2}\right), \\
& k\left(e_{h}^{2}-e_{l}^{2}\right)+\alpha \frac{s_{h}^{2}}{e_{h}}\left(A-\beta p+\gamma s_{h}\right)-\alpha \frac{s_{l}^{2}}{e_{l}}\left(A-\beta p+\gamma s_{l}\right)-\theta \frac{F}{s_{l}}>p \gamma\left(s_{h}-s_{l}\right) .
\end{aligned}
$$

According to the required stability conditions, these two scenarios in which enterprises can adopt speculative behavior and still reach a stable equilibrium state. If enterprises select the "Speculation" strategy and consumers have to buy the low-quality products, the government can, in theory, choose two different subsidy strategies to stabilize the evolutionary game system.

4.3.2. There May Be Three Equilibrium Points for Realistic Pure Strategy Solutions for the Three Participants. We must consider whether the stability conditions are feasible with the actual situation. The strategy spaces involving speculative behavior, such as \{Subsidizing enterprises, Speculation, Purchase $\}$ and \{Subsidizing consumers, Speculation, Purchase\}, should be analyzed taking into account consumers' actual purchase intentions. Consumer welfare will be reduced by the purchase of low-quality products when enterprises choose the "Speculation" strategy. Decreased consumer welfare will inevitably have a negative impact on consumer purchases. Thus, consumers are motivated to change their purchasing strategy. For the strategy space \{Subsidizing consumers, Speculation, Purchase\}, the government subsidizing for consumers can be seen as compensation for consumers to buy low-quality products. Consumers will persist with the purchasing strategy only when the subsidy provided by the government to consumers is greater than the loss in consumer welfare, that is, when equation (21) and the condition below are simultaneously satisfied:

$$
t\left(A-\beta(p-t)+\gamma s_{l}\right)>\gamma\left(s_{h}-s_{l}\right)\left[A-\beta(p-t)+\gamma\left(\frac{s_{h}+s_{l}}{2}\right)\right] .
$$

This strategy space \{Subsidizing enterprises, Speculation, Purchase $\}$ will also result in a reduction in consumer welfare. Consumers are therefore always willing to change the current situation without any subsidy under the implementation of the "Speculation" strategy by enterprises. The equilibrium point $(0,1,1)$ is unlikely to be an ESS when the reduction in consumer welfare is taken into account. Below, we confirm this position through numerical analysis.

The strategies \{Subsidizing enterprises, Effort, Purchase\} and \{Subsidizing consumers, Effort, Purchase $\}$ can satisfy equations (19) and (20) relating to evolutionary stability. Both enterprise and consumer strategies contribute to the long-term healthy development of the market. Under the government's different strategies, neither of the above participants has an incentive to change their strategies. We believe that these are the two evolutionarily stable results for all participants.

4.4. Discussion on a Scenario of Government Knowing Speculation. Considering even if the government chooses to subsidize enterprises, the enterprises may choose to do the speculation. Inspired by Tanimoto [50], we have the following discussion about the behaviors of government and enterprises. If the government prepares to subsidize enterprises, we assume that there exists a certain probability for knowing the speculative behavior chosen by enterprises. The parameter $q$ denotes the probability of knowing that enterprises select the "Speculation" strategy. In this case, the government will not provide subsidies for enterprises. Certainly, if enterprises select the "Effort" strategy, the probability $q$ makes no sense. And, this assumption does not consider the situation when the government subsidizes consumers, because the government does not provide R\&D 
subsidy for enterprises to improve products when subsidizing consumers. Since the discussion is mainly about the relationship between the government and enterprises, the payoff can be simplified as the following.

We assume that $a_{1}, b_{1}, c_{1}, d_{1}, e_{1}\left(a_{2}, b_{2}, c_{2}, d_{2}, e_{2}\right)$ represent the government's (enterprises) payoff under different situations. The government considers the probability of knowing the speculative behavior when the government prepares to subsidize consumers. Hence, $e_{1}$ and $e_{2}\left(c_{1}\right.$ and $\left.c_{2}\right)$ denote the payoff when the government (does not) knows the probability $q$. According to Table 5, the average benefits of the government and enterprises in the equilibrium point $(0,1)$ are $(1-q) c_{1}+q e_{1}$ and $(1-q) c_{2}+q e_{2}$, respectively. Based on the previous method to solve the replicator dynamics equation, the details are presented in the Appendix. The necessary and sufficient conditions for the four equilibrium points are shown in Table 6.

As shown in Figure 5, when the government may know the "Speculation" strategy of enterprises, the necessary and sufficient conditions for equilibrium points have changed in comparison with the conditions without $q$. Considering the government with the probability of knowing the "Speculation" strategy of enterprises, one would think that the equilibrium point $(0,1)$, that is, the strategy \{Subsiding enterprises, Speculation $\}$ will be avoided effectively. As shown in Figure 5(c), however, we are unable to claim that knowing the probability of the "Speculation" strategy of enterprises must have a positive influence on the government choice. Compared to the situation without $q$, the range of $\lambda_{1}$ is extended and the range of $\lambda_{2}$ is reduced (see Table 6) when the government may know speculative behavior of enterprises for the strategy \{Subsiding enterprises, Speculation\}. In Figure 5(c), the upper reduced shadow area results from the reduction in $\lambda_{2}$; the lower increased shadow area is caused by the increase in $\lambda_{1}$. Because the two shadow areas depend on the values of the payoff, we are unable to determine the size of the two shadow areas. Therefore, we cannot directly judge whether knowing the probability of speculative behavior of enterprises is really effective in avoiding the strategy \{Subsiding enterprises, Speculation\}.

Interestingly, knowing the probability of speculative behavior can indirectly influence the range of conditions for satisfying the strategy \{Subsiding enterprises, Effort\} and \{Subsidizing consumers, Speculation\}. In this case, the equilibrium point $(0,0)$ extends the range of condition by increased shadow area, because the average benefits of the strategy "Speculation" for enterprises are less than the benefits of the strategy "Effort" due to increased penalty when the government knows the probability of speculative behavior. Due to increased penalty and canceled subsidy cost, the government's average benefits of subsidizing enterprises are more than the benefits of the strategy "subsidizing consumers," and the range of condition is reduced for the equilibrium point $(1,1)$. Actually, the two opposite effects influence the range of condition of the equilibrium point $(0,1)$, and the inexplicit magnitude of the two effects impedes the estimate of range about satisfying the equilibrium point $(0,1)$.
TABle 5: Payoff matrix for the government and enterprises.

\begin{tabular}{cccc}
\hline & & \multicolumn{2}{c}{ Enterprises } \\
& & $\begin{array}{c}\text { Speculation } \\
(y)\end{array}$ & $\begin{array}{c}\text { Effort } \\
(1-y)\end{array}$ \\
\hline \multirow{2}{*}{ Government } & $\begin{array}{c}\text { Subsidizing consumers } \\
(x)\end{array}$ & $a_{1}, a_{2}$ & $b_{1}, b_{2}$ \\
& $\begin{array}{c}\text { Subsidizing enterprises } \\
(1-x)\end{array}$ & $c_{1}, c_{2}\left(\right.$ or $\left.e_{1}, e_{2}\right)$ & $d_{1}, d_{2}$ \\
\hline
\end{tabular}

Even if the government may know the probability of speculative behavior for enterprises when preparing to subsidize enterprises, it is also difficult to determine whether the equilibrium point $(0,1)$ can be effectively prevented. However, knowing the probability of speculative behavior indirectly causes two opposite effects for the equilibrium points $(0,0)$ and $(1,1)$.

4.5. Social Dilemma Analysis. Social dilemma is a fundamental conflict between immediate self-interset and longterm collective interest among participants in socioeconomic phenomena. For example, in our study, although the government subsidizes enterprises, enterprises are still able to choose to do speculation for self-interests regardless of the collective interest. A shortcut to the analysis of social dilemmas has thus far been reserved solely for dyadic games. We will utilize universal scaling parameters proposed by Tanimoto [50] to measure the dilemmas in the study based on the payoff matrix shown in Section 4.4. The strength of a dilemma that disturbs the promotion of cooperation is expressed as two types of universal parameters, namely, the strength of the gamble-intending dilemma $D_{g}^{\prime}$ and the strength of the risk-averting dilemma $D_{r}^{\prime}$.

To better depict the dilemma, we define that the participants' mutual cooperative strategy is \{Subsiding enterprises, Effort\}. On the other hand, the strategy \{Subsidizing consumers, Speculation\} is a mutual defection. In other words, subsidizing enterprises (consumers) is a cooperative (defected) behavior for the government; the "Effort" ("Speculation") strategy for enterprises represents cooperation (defection). In addition, we adopt a new expression to denote the payoff of four situations between the government and enterprises (that is, cooperation $(\mathrm{C})$ and cooperation (C), defection (D) and cooperation (C), cooperation (C) and defection (D), defection (D) and defection (D)). According to the definitions of payoff for the government and enterprises mentioned in Section 3.2, we use the difference value of social welfare minus profit of enterprises to express the payoff of each situation. For instance, $b_{1}-b_{2}$ represents the payoff of the situation (defection, cooperation). Because the difference values consist of subsidy cost bore by the government and production cost and fines (if any) bore by enterprises, the value is determined by the government and enterprises.

Depending on the two dilemma strengths $\left(D_{g}^{\prime}\right.$ and $\left.D_{r}^{\prime}\right)$, we analyze all dilemma situations in the study. The details are presented in the Appendix. When $d_{1}-d_{2}-a_{1}+a_{2}>0$, 
TABLE 6: The equilibrium conditions with $q$ and without $q$.

\begin{tabular}{|c|c|c|c|c|}
\hline \multirow{2}{*}{ ESS } & \multicolumn{2}{|c|}{ Sign of $\lambda_{1}$} & \multicolumn{2}{|c|}{ Sign of $\lambda_{2}$} \\
\hline & Without $q$ & With $q$ & Without $q$ & With $q$ \\
\hline$(0,0)$ & $b_{1}-d_{1}<0$ & $b_{1}-d_{1}<0$ & $c_{2}-d_{2}<0$ & $(1-q) c_{2}+q e_{2}-d_{2}<0$ \\
\hline$(0,1)$ & $a_{1}-c_{1}<0$ & $a_{1}-(1-q) c_{1}-q e_{1}<0$ & $c_{2}-d_{2}>0$ & $(1-q) c_{2}+q e_{2}-d_{2}>0$ \\
\hline$(1,0)$ & $b_{1}-d_{1}>0$ & $b_{1}-d_{1}>0$ & $a_{2}-b_{2}<0$ & $a_{2}-b_{2}<0$ \\
\hline$(1,1)$ & $a_{1}-c_{1}>0$ & $a_{1}-(1-q) c_{1}-q e_{1}>0$ & $a_{2}-b_{2}>0$ & $a_{2}-b_{2}>0$ \\
\hline
\end{tabular}

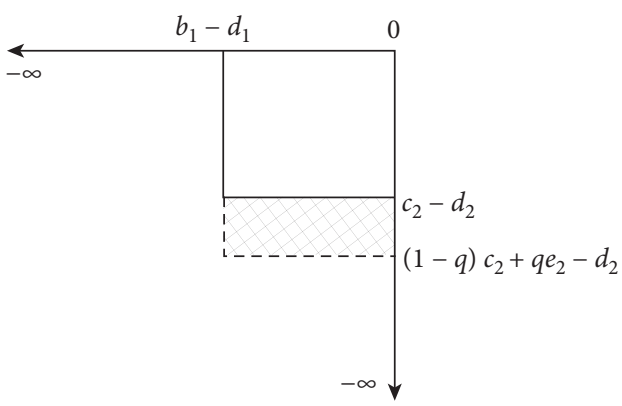

(a)

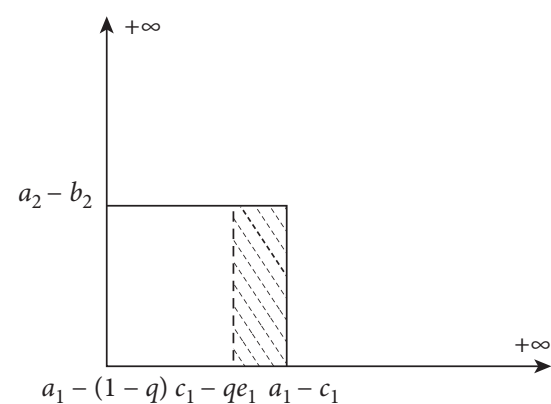

(b)

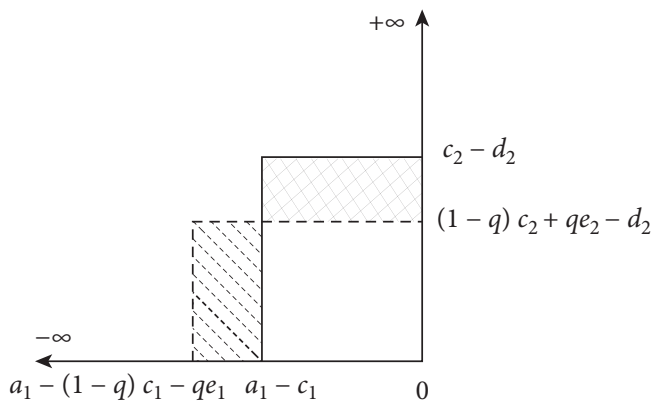

(c)

FIgURE 5: The condition range changes. (a) The change in the condition of $(0,0)$. (b) The change in the condition of $(1,1)$. (c) The change in the condition of $(0,1)$.

the conditions of different dilemma types are summarized in Table 7 .

When $d_{1}-d_{2}-a_{1}+a_{2}<0$, the conditions of different dilemma types are showed in Table 8 .

The payoff is determined by the magnitude of $a_{i}, b_{i}, c_{i}, d_{i}$, $e_{i}$, which in turn determines the nature of the dilemma. If, for example, the order is $b_{1}-b_{2}>d_{1}-d_{2}>a_{1}-a_{2}>(1-q)$ $c_{1}+q e_{1}-(1-q) c_{2}-q e_{2}$, then the game is known as the Prisoner's Dilemma (PD). Besides, although knowing the probability of speculative behavior does not necessarily avoid speculation of enterprises, it can be used to distinguish different types of dilemmas.

\section{Numerical Simulation}

In this section, Matlab 2016b is utilized to explore the impact of a change in the value of key parameters on the probability of different strategy choices and evolutionary paths among participants. We also analyze the stability of the evolutionary results and validate the claims made above. When setting the initial parameters, we conform to the internal logical relations between the parameters. The initial values of the parameters of the dynamic system model are as follows:

$$
\begin{aligned}
A & =100, \\
p & =25, \\
t & =5, \\
\beta & =3, \\
\gamma & =20, \\
\alpha & =2, \\
k & =28, \\
F & =3000 .
\end{aligned}
$$

5.1. Impact Analysis of Key Parameters on Government Decision-Making. Under the premise of keeping the initial parameters, we analyze the effect of changing $\Delta s$ and $e_{l}$ on the evolutionary path of the government. For ease of exposition, $\Delta s\left(\Delta s=s_{h}-s_{l}\right)$ is used to indicate the degree of 
TABLE 7: The conditions of different dilemma types.

\begin{tabular}{lcccc}
\hline Game class & Sign of $D_{g}^{\prime}$ & Sign of $D_{r}^{\prime}$ & Equilibrium strategy & Conditions \\
\hline PD & $D_{g}^{\prime}>0$ & $D_{r}^{\prime}>0$ & $(1,1)$ & $b_{1}-b_{2}-d_{1}+d_{2}>0$ and $q<a_{1}-a_{2}-c_{1}+c_{2} / e_{1}-e_{2}-c_{1}+c_{2}$ \\
Chicken & $D_{q}^{\prime}>0$ & $D_{r}^{\prime}<0$ & Internal equilibrium & $b_{1}-b_{2}-d_{1}+d_{2}>0$ and $q>a_{1}-a_{2}-c_{1}+c_{2} / e_{1}-e_{2}-c_{1}+c_{2}$ \\
Stag hunt & $D_{q}^{\prime}<0$ & $D_{r}^{\prime}>0$ & $(0,1)$ or $(1,0)$ & $b_{1}-b_{2}-d_{1}+d_{2}<0$ and $q<a_{1}-a_{2}-c_{1}+c_{2} / e_{1}-e_{2}-c_{1}+c_{2}$ \\
Trivial & $D_{g}^{\prime}<0$ & $D_{r}^{\prime}<0$ & $(0,0)$ & $b_{1}-b_{2}-d_{1}+d_{2}<0$ and $q>a_{1}-a_{2}-c_{1}+c_{2} / e_{1}-e_{2}-c_{1}+c_{2}$ \\
\hline
\end{tabular}

TABLe 8: The conditions of different dilemma types.

\begin{tabular}{lcccc}
\hline Game class & Sign of $D_{g}^{\prime}$ & Sign of $D_{r}^{\prime}$ & Equilibrium strategy & Conditions \\
\hline PD & $D_{q}^{\prime}>0$ & $D_{r}^{\prime}>0$ & $(1,1)$ & $b_{1}-b_{2}-d_{1}+d_{2}<0$ and $q>a_{1}-a_{2}-c_{1}+c_{2} / e_{1}-e_{2}-c_{1}+c_{2}$ \\
Chicken & $D_{q}^{\prime}>0$ & $D_{r}^{\prime}<0$ & Internal equilibrium & $b_{1}-b_{2}-d_{1}+d_{2}<0$ and $q<a_{1}-a_{2}-c_{1}+c_{2} / e_{1}-e_{2}-c_{1}+c_{2}$ \\
Stag hunt & $D_{g}^{\prime}<0$ & $D_{r}^{\prime}>0$ & $(0,1)$ or $(1,0)$ & $b_{1}-b_{2}-d_{1}+d_{2}>0$ and $q>a_{1}-a_{2}-c_{1}+c_{2} / e_{1}-e_{2}-c_{1}+c_{2}$ \\
Trivial & $D_{g}^{\prime}<0$ & $D_{r}^{\prime}<0$ & $(0,0)$ & $b_{1}-b_{2}-d_{1}+d_{2}>0$ and $q<a_{1}-a_{2}-c_{1}+c_{2} / e_{1}-e_{2}-c_{1}+c_{2}$ \\
\hline
\end{tabular}

enterprise speculation. The larger $\Delta s$ is, the greater is the degree of speculation by enterprises. Furthermore, recall that $k e_{l}^{2}$ ( $k$ is a constant) represents the $\mathrm{R} \& \mathrm{D}$ subsidy from the government to enterprises. A larger $e_{l}$ indicates that the government provides a higher subsidy to enterprises. We assume that $e_{h}=8$ is unchanged because we intend to simultaneously investigate the impacts of the effort gap on government decision-making with respect to enterprises' technical improvement and government subsidy. The other parameters are $s_{h}=3, s_{l}=1.5\left(s_{l}=2.5\right)$, and $e_{l}$ is between 2 and 6 , with an interval of 2 .

As shown in Figure 6, when the degree of speculation $\Delta s$ $\left(s_{h}=3, s_{l}=1.5\right)$ is high, the speed of convergence to 0 (that is, the strategy of subsidizing enterprises) is faster than when the degree of speculation is low $\left(s_{h}=3, s_{l}=2.5\right)$ under the same subsidy conditions (that is, when $e_{l}$ is the same in both levels of speculation). The government prefers to select the strategy of subsidizing enterprises when enterprise speculation is high; the degree of speculation by enterprises therefore has an obvious impact on the government's choice of strategy. With the increase of $e_{l}$ (that is, when the subsidy to enterprises increases and the effort gap decreases), the speed of convergence to the stable strategy (subsidizing enterprises) will be slowed down regardless of the degree of speculation by enterprises. The two sub-graphs of Figure 6 show that the government is not willing to subsidize enterprises in this case; the government is inclined to choose to subsidize consumers when $e_{l}$ is relatively high. From Figure 6 , we find that $\Delta s$ and $e_{l}$ have different effects on the government's choice of strategy. The above numerical results are consistent with those discussed in Figure 2.

5.2. Stability Analysis of Evolutionary Results. In the previous analysis, we argue that the strategy space \{Subsidizing enterprises, Speculation, Purchase \} cannot be an ESS in practice when considering consumers' purchase intentions. We focus on this scenario to conduct a numerical study that further analyzes evolutionary stability. Here, the parameters are $s_{h}=3, s_{l}=2.5, e_{h}=8, e_{l}=3$ and $F=2800(F=3000)$ under a soft punishment situation (harsh punishment situation).
If the government subsidy to enterprises and the degree of speculation are both low $\left(e_{l}=3\right.$ and $\left.\Delta s=0.5\right)$, it can be seen from Figure 7 that the government and enterprises continue to oscillate and show periodic changes in this strategy space. This also confirms that the strategy space \{Subsidizing enterprises, Speculation, Purchase\} (that is, the equilibrium point $(0,1,1))$ cannot be a stable strategy when considering the possible changes in consumers' strategy due to reduced consumer welfare. The two subgraphs of Figure 7 show that if the government continues to subsidize enterprises with a low subsidy, enterprises will increasingly select the "Speculation" strategy over time. The level of subsidy used by the government to compensate for the loss of consumer welfare (that is, subsidizing consumers when consumers buy low-quality products because of the speculative behavior of enterprises) is relatively low due to the low degree of speculation. The government will therefore not consider increasing its subsidy to enterprises. The speculative behavior of enterprises then induces a sharp increase in the probability of the government subsidizing consumers. Without the subsidy provided by the government for technical improvement, the production cost of enterprises will increase. The speculative behavior of enterprises simultaneously reduces consumers' desire to purchase products. Enterprises therefore must return to the "Effort" strategy to provide normal-quality products and strive for government subsidies to mitigate their high production costs. Given the change in enterprises' strategy, the government will also adjust its strategy and start subsidizing enterprises again. Obviously, there is a lag in the change in government strategy in the face of the change in enterprise strategy. The intuition behind this result is that there is a time lag between enterprises changing their strategy to provide low-quality products to consumers and the government receiving supervision feedback from its internal mechanism and from consumers, and vice versa. Figure 7 (b) reflects that an increase in fines will extend the period before enterprises engage in speculative behavior. High penalties thus effectively prevent enterprises from engaging in speculation when the subsidy to enterprises is low. 

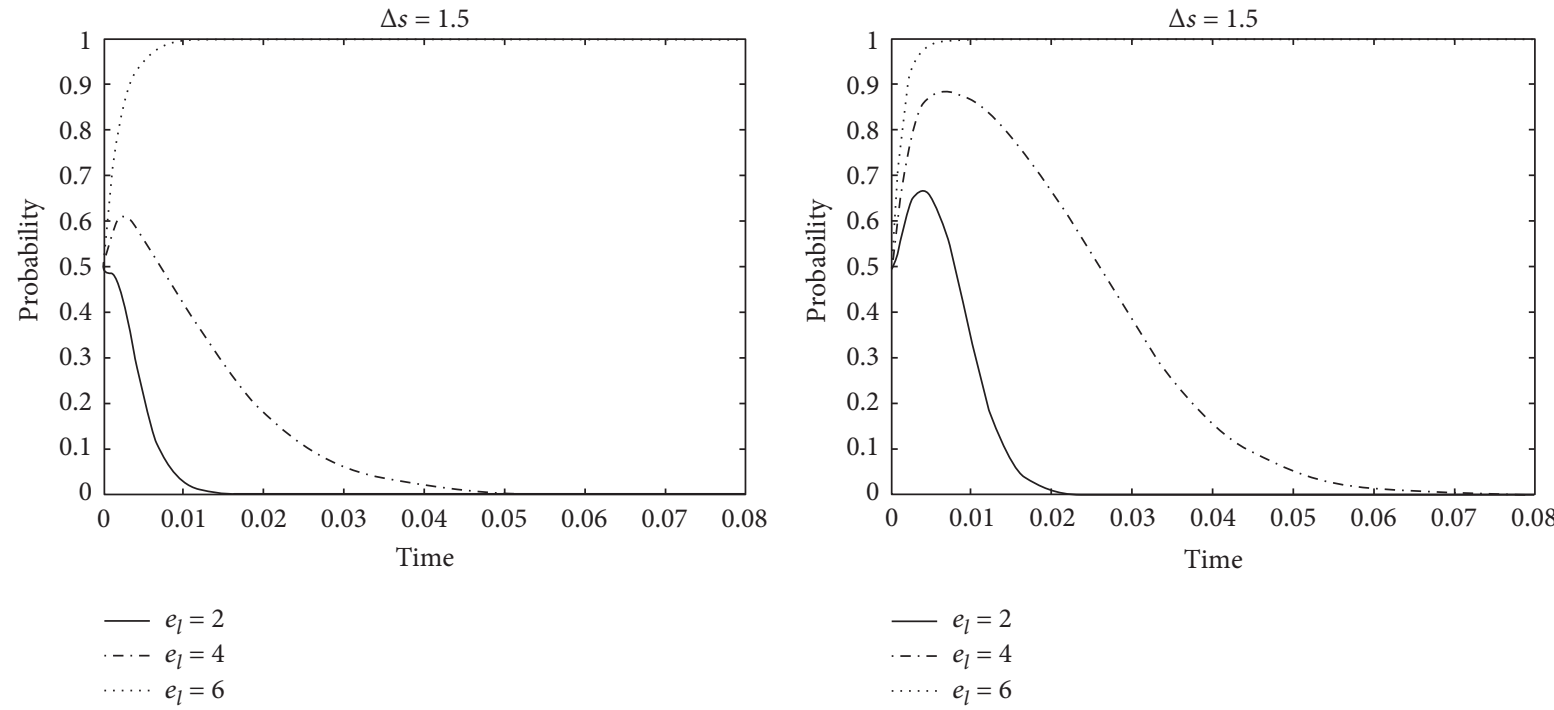

(a)

(b)

FIGURE 6: Evolutionary path of the government. (a) The degree of speculation $(\Delta s)$ is high. (b) The degree of speculation $(\Delta s)$ is low.

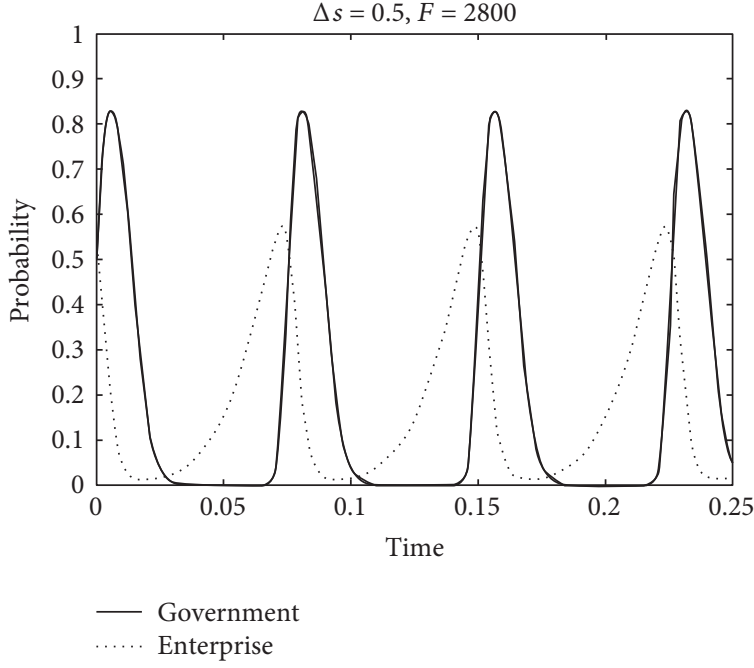

(a)

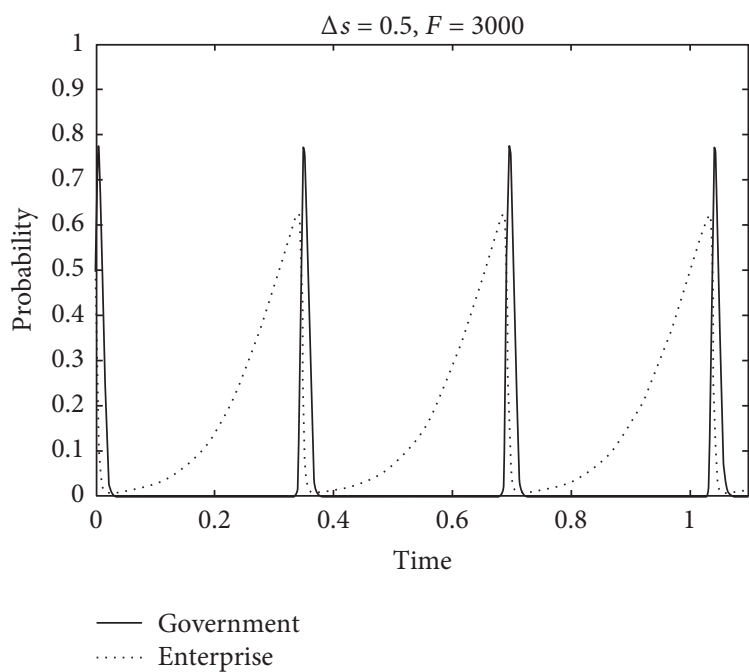

(b)

Figure 7: Evolutionary path of the government and enterprises. (a) Punishment $(F)=2800$. (b) Punishment $(F)=3000$.

\section{Conclusions}

To promote consumption and restrain the speculative behavior of enterprises, we create a tripartite evolutionary game scenario (the government, enterprises, and consumers) under a subsidy and punishment mechanism. Four theoretically evolutionarily stable states are proposed in this study through the replicator dynamic system. We explore the influence of key factors on the evolutionary paths and discuss the feasibility of these stable states through numerical simulation. The main conclusions of this paper are as follows:

(1) In the evolutionary game used in this study, the strategy spaces \{Subsidizing enterprises, Effort,
Purchase $\}$ and \{Subsidizing consumers, Effort, Purchase could both reach an evolutionarily stable state in which all participants have no incentive to change their strategy. These two strategy sets are considered to be satisfactory evolutionary game results because the behavior of enterprises and consumers they entail contribute to the long-term healthy development of the market. It is common for the government to stimulate consumer purchasing behavior by subsidizing consumers, such as "Home Appliances in Rural Homes," a subsidy program initiated by the Chinese government. The program aims to help rural residents purchase quality household appliances offered by reputable and 
trustworthy enterprises like Haier and Little Swan. Meanwhile, the subsidies provided by the government to enterprises, especially for R\&D subsidies for product improvement, are usually determined according to the investment in R\&D of enterprises (that is, the efforts of the enterprises). The strategy set \{Subsidizing consumers, Speculation, Purchase\} is an evolutionarily stable state only when the subsidy provided by the government to consumers is higher than the welfare loss caused by enterprise speculation behaviors. This phenomenon is not common in practice, because the government will pay for the speculative behavior of enterprises. In turn, enterprises often sell their defective products by subsidizing consumers. This method will make consumers think that these products are worth purchasing through the subsidies of enterprises.

(2) The strategy space \{Subsidizing enterprises, Speculation, Purchase is unlikely to be in an evolutionarily stable state. The government will not accept that enterprises choose to speculate even if they are subsidized by the government. This is why some local governments subsidize enterprises according to R\&D investment of enterprises (that is, performance of effort). On the other hand, consumers are motivated to change their strategy because the speculative behavior of enterprises will reduce consumer welfare. Consumers therefore do not pursue the "Purchase" strategy in the absence of a government subsidy that compensates for reduced consumer welfare. For instance, when enterprises' speculation is not serious and the subsidy of the government to enterprises is low, the behavior of the government and enterprises fails to stay in a constant state. There is also a time lag between the cyclical changes in the strategies used by the government and enterprises because the consumer market needs to perceive and respond to the changes in product quality. Besides, to mitigate the cost pressures on subsidies, a government with a limited budget could adopt harsh punishment to extend the period before enterprises adopt speculative behavior.

(3) Both the degree of speculation and the level of effort for technical improvement have an obvious impact on the evolutionary path of the government. The government is increasingly likely to choose to subsidize consumers as the quality gap between the two types of products narrows and the cost to the government of subsidizing enterprises increases. The government prefers to subsidize enterprises when enterprise speculation is serious or when enterprises invest more to improve their production technology. This is consistent with what we have observed in the market. Most of the time, the government will choose to subsidize consumers. Only when an enterprise invests a lot in product development and innovation, the government prefers to subsidize the enterprise rather than the consumer and encourage these enterprises to continuously innovate and improve their products. On the contrary, the government always imposes severe penalties on enterprises with more serious speculation.

(4) Although the government may capture the probability of speculative behavior for enterprises, we still cannot determine whether the strategy \{Subsiding enterprises, Speculation\} can be avoided effectively.

The following aspects are worth discussing in future research. First, we assume that the product price is constant in our study. However, the price may be different when enterprises produce a low-quality product. The results of our study will therefore be more practically applicable if studied in a context featuring different prices. Second, we do not consider the competitive relationship between enterprises. The existence of competition will influence product price and product demand. This study can serve as a valuable reference for the ESS of participants under market competition. Third, it would be interesting to study how enterprises allocate government subsidies to improve their production technology when they offer more than one product.

\section{Appendix}

\section{A. Proof of Section 4.3}

(1) There are seven internal equilibrium points for the tripartite evolutionary game. Limited to the space of this article, we give some internal equilibrium results such as:

$$
\begin{aligned}
& E_{9} \cdot\left(\frac{2 A \gamma s_{h}+A^{2}+\beta^{2} p^{2}-s_{h}^{2} \gamma^{2}-2 \beta p \gamma s_{h}-2 A \beta p}{\beta t\left(2 A+2 \gamma s_{h}+\beta t-2 \beta p\right)}, 0, \frac{2 k\left(e_{h}^{2}-e_{l}^{2}\right)}{t\left(\beta^{2} t+2 \beta \gamma s_{h}+2 A \beta+4 \beta p-2 \beta^{2} p-2 \gamma s_{h}-2 \beta t-2 A\right)}\right), \\
& E_{10} \cdot\left(\frac{2 A \gamma s_{l}+A^{2}+\beta^{2} p^{2}-s_{l}^{2} \gamma^{2}-2 \beta p \gamma s_{h}-2 A \beta p}{\beta t\left(2 A+2 \gamma s_{l}+\beta t-2 \beta p\right)}, 1, \frac{2 k\left(e_{h}^{2}-e_{l}^{2}\right)}{t\left(\beta^{2} t+2 \beta \gamma s_{h}+2 A \beta+4 \beta p-2 \beta^{2} p-2 \gamma s_{h}-2 \beta t-2 A\right)}\right) \\
& E_{11} \cdot\left(\frac{k s_{l} e_{l}^{2}+\delta F-k s_{l} e_{h}^{2}}{k s_{l} e_{l}^{2}}, \frac{e_{h}^{2}-e_{l}^{2}}{e_{h}^{2}}, 0\right) .
\end{aligned}
$$


(2)

(1) According to Lyapunov stability theory, if $(0,0$, 1) is an ESS, $\lambda_{1}<0$ and $\lambda_{2}<0$ must simultaneously be true. We need to determine $F^{\prime}(x)$ and $F^{\prime}(y)$ (see the replication dynamic system in Section 4.2 and the Jacobian matrix in Section 4.3) and ensure that $F^{\prime}(x)$ and $F^{\prime}(y)$ are both negative. Hence, for the equilibrium point $(0,0$, 1), $\quad t \beta A+2 t \beta p+t \beta \gamma s_{h}+\left(\beta^{2} t^{2} / 2\right)-t \gamma s_{h}-t A-$ $\beta t^{2}-k e_{h}^{2}+k e_{l}^{2}<0$ and $k e_{h}^{2}-k e_{l}^{2}-\left(\alpha \gamma s_{l}^{3}+\alpha s_{l}^{2}\right.$ $\left.(A-\beta p) / e_{l}\right)+\gamma s_{l} p-\gamma s_{n} p+\left(\alpha s_{h}^{2}(A-\beta p+\gamma\right.$ $\left.\left.s_{h}\right) / e_{l}\right)-\theta\left(F / s_{l}\right)<0$. That is, $k e_{l}^{2}<k e_{h}^{2}+t(1-$ $\beta)\left(A-\beta p+\gamma s_{h}\right)-\beta t(p-t+(\beta t / 2))$ and $k\left(e_{h}^{2}-\right.$ $\left.e_{l}^{2}\right)+\alpha\left(s_{h}^{2} / e_{h}\right)\left(A-\beta p+\gamma s_{h}\right)-\alpha\left(s_{l}^{2} / e_{l}\right)(A-\beta p+$ $\left.\gamma s_{l}\right)-\theta\left(F / s_{l}\right)<p \gamma\left(s_{h}-s_{l}\right)$. Similarly, if $(1,0,1)$ is an ESS, $F^{\prime}(x)<0$ and $F^{\prime}(y)<0$ when $x=1$, $y=0$, and $z=1$. When $k e_{l}^{2}>k e_{h}^{2}+t(1-\beta)(A-$ $\left.\beta p+\gamma s_{h}\right)-\beta t(p-t+(\beta t / 2))$ and $k e_{h}^{2}+\alpha\left(s_{h}^{2} /\right.$ $\left.e_{h}\right)\left(A-\beta p+\gamma s_{h}\right)-\alpha\left(s_{l}^{2} / e_{l}\right)\left(A-\beta p+\gamma s_{l}\right)-\theta$ $\left(F / s_{l}\right)<p \gamma\left(s_{h}-s_{l}\right)$, the strategy space Subsidizing consumers, Effort, Purchase\} will be an ESS.

As in the above case, the equilibrium points $(0,1$, $1)$ and $(1,1,1)$ can be an ESS only when the conditions $F^{\prime}(x)<0$ and $F^{\prime}(y)<0$ simultaneously hold.

(2) If enterprises offer low-quality products, consumer welfare will be reduced due consumers purchasing low-quality products. For the strategy space \{Subsidizing consumers, Speculation, Purchase\}, consumers are likely to change their strategy. To maintain consumers' purchasing decisions, the government subsidy should be greater than the loss in consumer welfare due to the purchase of low-quality products, that is, the condition $t\left(A-\beta(p-t)+\gamma s_{l}\right)>((A-\beta(p-t)$ $\left.\left.+\gamma s_{h}\right)^{2} / 2\right)-\left(\left(A-\beta(p-t)+\gamma s_{l}\right)^{2} / 2\right) \quad$ should hold.

\section{B. Proof of Section 4.4}

Without $q$ :

$$
\begin{aligned}
U_{11} & =\left(\begin{array}{ll}
1 & 0
\end{array}\right)\left[\begin{array}{ll}
a & b_{1} c_{1}
\end{array}\right]\left(\begin{array}{c}
y \\
1-y
\end{array}\right)=y a_{1}+(1-y) b_{1} \\
U_{12} & =\left(\begin{array}{ll}
0 & 1
\end{array}\right)\left[\begin{array}{ll}
a_{1} & b_{1} \\
c_{1} & d_{1}
\end{array}\right]\left(\begin{array}{cc}
y & y \\
1- & y
\end{array}\right)=y c_{1}+(1-y) d_{1} \\
U_{21} & =\left(\begin{array}{ll}
x & 1-x
\end{array}\right)\left[\begin{array}{ll}
a_{2} & b_{2} \\
c_{2} & d_{2}
\end{array}\right]\left(\begin{array}{l}
1 \\
0
\end{array}\right)=x a_{2}+(1-x) c_{2} \\
U_{22} & =\left(\begin{array}{ll}
x & 1-x
\end{array}\right)\left[\begin{array}{ll}
a_{2} & b_{2} \\
c_{2} & d_{2}
\end{array}\right]\left(\begin{array}{l}
0 \\
1
\end{array}\right)=x b_{2}+(1-x) d_{2}
\end{aligned}
$$

The replicator dynamics equations:

$$
\begin{aligned}
& F^{\prime}(x)=(1-2 x)\left(U_{11}-U_{12}\right)=(1-2 x)\left[y\left(a_{1}-c_{1}\right)+(1-y)\right. \\
& \left.\left(b_{1}-d_{1}\right)\right] \\
& F^{\prime}(y)=(1-2 y)\left(U_{21}-U_{22}\right)=(1-2 y)\left[x\left(a_{2}-b_{2}\right)+(1-x)\right. \\
& \left.\left(c_{2}-d_{2}\right)\right]
\end{aligned}
$$

(1) The necessary and sufficient conditions for the equilibrium point $(0,0)$ are $\lambda_{1}<0$ and $\lambda_{2}<0$. The following conditions are sought:

$$
\begin{aligned}
& b_{1}-d_{1}<0, \\
& c_{2}-d_{2}<0
\end{aligned}
$$

(2) The necessary and sufficient conditions for the equilibrium point $(0,1)$ are $\lambda_{1}<0$ and $\lambda_{2}<0$. We now require that

$$
\begin{aligned}
& a_{1}-c_{1}<0, \\
& c_{2}-d_{2}>0 .
\end{aligned}
$$

(3) The necessary and sufficient conditions for the equilibrium point $(0,1)$ are $\lambda_{1}<0$ and $\lambda_{2}<0$. We seek the following conditions:

$$
\begin{aligned}
& b_{1}-d_{1}>0, \\
& a_{2}-b_{2}<0
\end{aligned}
$$

(4) The necessary and sufficient conditions for the equilibrium point $(0,1)$ are $\lambda_{1}<0$ and $\lambda_{2}<0$. The following conditions are satisfied:

$$
\begin{aligned}
& a_{1}-c_{1}>0, \\
& a_{2}-b_{2}>0 .
\end{aligned}
$$

With $q$ :

$$
\begin{aligned}
& U_{11}=\left(\begin{array}{ll}
1 & 0
\end{array}\right)\left[\begin{array}{cc}
a_{1} & b_{1} \\
(1-q) c_{1}+q e_{1} & d_{1}
\end{array}\right]\left(\begin{array}{c}
y \\
1-y
\end{array}\right)= \\
& y a_{1}+(1-y) b_{1} \\
& U_{12}=\left(\begin{array}{ll}
0 & 1
\end{array}\right)\left[\begin{array}{cc}
a_{1} & b_{1} \\
(1-q) c_{1}+q e_{1} & d_{1}
\end{array}\right]\left(\begin{array}{c}
y \\
1-y
\end{array}\right)= \\
& y\left[(1-q) c_{1}+q e_{1}\right]+(1-y) d_{1} \\
& U_{21}=\left(\begin{array}{ll}
x & 1-x
\end{array}\right)\left[\begin{array}{cc}
a_{2} & b_{2} \\
(1-q) c_{2}+q e_{2} & d_{2}
\end{array}\right]\left(\begin{array}{l}
1 \\
0
\end{array}\right)= \\
& x a_{2}+(1-x)\left[(1-q) c_{2}+q e_{2}\right] \\
& U_{22}=\left(\begin{array}{ll}
x & 1-x
\end{array}\right)\left[\begin{array}{cc}
a_{2} & b_{2} \\
(1-q) c_{2}+q e_{2} & d_{2}
\end{array}\right]\left(\begin{array}{l}
0 \\
1
\end{array}\right)= \\
& x b_{2}+(1-x) d_{2}
\end{aligned}
$$

The replicator dynamics equations:

$$
\begin{aligned}
& F^{\prime}(x)=(1-2 x)\left\{y\left[a_{1}-(1-q) c_{1}-q e_{1}\right]+(1-y)\right. \\
& \left.\left(b_{1}-d_{1}\right)\right\} \\
& F^{\prime}(y)=(1-2 y)\left\{x\left(a_{2}-b_{2}\right)+(1-x)[(1-q)\right. \\
& \left.\left.c_{2}+q e_{2}-d_{2}\right]\right\}
\end{aligned}
$$

(5) The necessary and sufficient conditions for the equilibrium point $(0,0)$ are $\lambda_{1}<0$ and $\lambda_{2}<0$. The following conditions are sought:

$$
\begin{array}{r}
b_{1}-d_{1}<0 \\
(1-q) c_{2}+q e_{2}-d_{2}<0
\end{array}
$$


(6) The necessary and sufficient conditions for the equilibrium point $(0,1)$ are $\lambda_{1}<0$ and $\lambda_{2}<0$. We now require that

$$
\begin{aligned}
& a_{1}-(1-q) c_{1}-q e_{1}<0, \\
& (1-q) c_{2}+q e_{2}-d_{2}>0 .
\end{aligned}
$$

(7) The necessary and sufficient conditions for the equilibrium point $(0,1)$ are $\lambda_{1}<0$ and $\lambda_{2}<0$. we seek the following conditions:

$$
\begin{aligned}
& b_{1}-d_{1}>0, \\
& a_{2}-b_{2}<0 .
\end{aligned}
$$

(8) The necessary and sufficient conditions for the equilibrium point $(0,1)$ are $\lambda_{1}<0$ and $\lambda_{2}<0$. The following conditions are satisfied:

$$
\begin{array}{r}
a_{1}-(1-q) c_{1}-q e_{1}>0, \\
a_{2}-b_{2}>0 .
\end{array}
$$

\section{Proof of Section 4.5}

Based on the work of Tanimoto [50], if $D_{g}^{\prime}, D_{r}^{\prime}>0$, the ultimate state is mutual defection (i.e., $(1,1)$ ); if $D_{g}^{\prime}<0$ and $D_{r}^{\prime}>0$, the game, characterized by bistability, that is, there exists $(0,1)$ and $(1,0)$; if $D_{g}^{\prime}>0$ and $D_{r}^{\prime}<0$, there is an internal equilibrium; if $D_{g}^{\prime}<0$ and $D_{r}^{\prime}<0$, cooperation dominates defection, that is, $(0,0)$ is the ultimate state.

(1) If $D_{g}^{\prime}, D_{r}^{\prime}>0$, with the following substitution:

$$
\begin{aligned}
& D_{g}^{\prime}=\frac{T-R}{R-P}=\frac{b_{1}-b_{2}-d_{1}+d_{2}}{d_{1}-d_{2}-a_{1}+a_{2}}, \\
& D_{r}^{\prime}=\frac{P-S}{R-P}=\frac{a_{1}-a_{2}-(1-q) c_{1}-q_{1}+(1-q) c_{2}+q_{2}}{d_{1}-d_{2}-a_{1}+a_{2}} .
\end{aligned}
$$

Here, participants for mutual cooperation and defection, respectively, receive the reward payoff $R$ and the punishment payoff $P$. If a cooperator is exploited by a defector, then the former receives a sucker's payoff $S$, while the latter receives the temptation payoff $T$.

Hence, when $d_{1}-d_{2}-a_{1}+a_{2}>0, b_{1}-b_{2}-d_{1}+d_{2}>0$ and $q<a_{1}-a_{2}-c_{1}+c_{2} / e_{1}-e_{2}-c_{1}+c_{2}$; while when $d_{1}-d_{2}-a_{1}+a_{2}<0, \quad b_{1}-b_{2}-d_{1}+d_{2}<0$ and $q>a_{1}-a_{2}-c_{1}+c_{2} / e_{1}-e_{2}-c_{1}+c_{2}$.

(2) If $D_{g}^{\prime}>0$ and $D_{r}^{\prime}<0$, the following conditions are sought:

$$
\begin{aligned}
& D_{g}^{\prime}=\frac{T-R}{R-P}=\frac{b_{1}-b_{2}-d_{1}+d_{2}}{d_{1}-d_{2}-a_{1}+a_{2}}>0 \\
& D_{r}^{\prime}=\frac{P-S}{R-P}=\frac{a_{1}-a_{2}-(1-q) c_{1}-q_{1}+(1-q) c_{2}+q_{2}}{d_{1}-d_{2}-a_{1}+a_{2}}<0
\end{aligned}
$$

When $d_{1}-d_{2}-a_{1}+a_{2}>0, \quad b_{1}-b_{2}-d_{1}+d_{2}>0$ and $q>a_{1}-a_{2}-c_{1}+c_{2} / e_{1}-e_{2}-c_{1}+c_{2}$; while when $d_{1}-d_{2}-a_{1}+a_{2}<0, \quad b_{1}-b_{2}-d_{1}+d_{2}<0 \quad$ and $q<a_{1}-a_{2}-c_{1}+c_{2} / e_{1}-e_{2}-c_{1}+c_{2}$.

(3) If $D_{g}^{\prime}<0$ and $D_{r}^{\prime}>0$, we now require that

$$
\begin{aligned}
& D_{g}^{\prime}=\frac{T-R}{R-P}=\frac{b_{1}-b_{2}-d_{1}+d_{2}}{d_{1}-d_{2}-a_{1}+a_{2}}<0, \\
& D_{r}^{\prime}=\frac{P-S}{R-P}=\frac{a_{1}-a_{2}-(1-q) c_{1}-q_{1}+(1-q) c_{2}+q_{2}}{d_{1}-d_{2}-a_{1}+a_{2}}>0 .
\end{aligned}
$$

When $d_{1}-d_{2}-a_{1}+a_{2}>0, \quad b_{1}-b_{2}-d_{1}+d_{2}<0$ and $q<a_{1}-a_{2}-c_{1}+c_{2} / e_{1}-e_{2}-c_{1}+c_{2}$; while when $d_{1}-d_{2}-a_{1}+a_{2}<0, \quad b_{1}-b_{2}-d_{1}+d_{2}>0$ and $q>a_{1}-$ $a_{2}-c_{1}+c_{2} / e_{1}-e_{2}-c_{1}+c_{2}$.

(4) If $D_{g}^{\prime}, D_{r}^{\prime}<0$, the following conditions are satisfied: $D_{g}^{\prime}=\frac{T-R}{R-P}=\frac{b_{1}-b_{2}-d_{1}+d_{2}}{d_{1}-d_{2}-a_{1}+a_{2}}<0$, $D_{r}^{\prime}=\frac{P-S}{R-P}=\frac{a_{1}-a_{2}-(1-q) c_{1}-q_{1}+(1-q) c_{2}+q_{2}}{d_{1}-d_{2}-a_{1}+a_{2}}<0$.

When $d_{1}-d_{2}-a_{1}+a_{2}>0, \quad b_{1}-b_{2}-d_{1}+d_{2}<0$ and $q>a_{1}-a_{2}-c_{1}+c_{2} / e_{1}-e_{2}-c_{1}+c_{2}$; while when $d_{1}-d_{2}-a_{1}+a_{2}<0, b_{1}-b_{2}-d_{1}+d_{2}>0$ and $q<a_{1}-$ $a_{2}-c_{1}+c_{2} / e_{1}-e_{2}-c_{1}+c_{2}$.

\section{Data Availability}

No data were used to support this study.

\section{Conflicts of Interest}

The authors declare that there are no conflicts of interest regarding the publication.

\section{Acknowledgments}

This work was supported by Fundamental Research Funds for the Central Universities (Grant no. JBK2107075).

\section{References}

[1] Q. K. Wang, "Aux air conditioning energy efficiency label is not up to standard and is punished by top grid," 2020, http:// www.chinanews.com/cj/2020/04-11/9153700.shtml.

[2] J. R. Peng, "Haidilao apologizes for the price increase: prices immediately return to pre-closing standards," 2020, http:// www.chinanews.com/cj/2020/04-10/9153281.shtml.

[3] O. Coibion, Y. Gorodnichenko, and M. Weber, "The Cost of the COVID-19 Crisis: Lockdowns," Macroeconomic Expectations, and Consumer Spending, National Bureau of Economic Research (NBER), Cambridge, MA, USA, 2020.

[4] S. R. Baker, R. A. Farrokhnia, S. Meyer, M. Pagel, and C. Yannelis, "Income, Liquidity, and the Consumption Response to the 2020 Economic Stimulus Payments," National 
Bureau of Economic Research (NBER), Cambridge, MA, USA, 2020.

[5] Q. R. Zhang, "Ministry of Commerce: since the outbreak of the epidemic, more than 19 billion yuan of vouchers have been issued in 28 provinces and 170 cities," 2020, http:// finance.china.com.cn/news/20200508/5268328.shtml.

[6] S. Alizamir, F. Iravani, and H. Mamani, "An analysis of price vs. Revenue protection: government subsidies in the agriculture industry," Management Science, vol. 65, no. 1, pp. 32-49, 2019.

[7] J. J. Yu, C. S. Tang, and Z.-J. M. Shen, "Improving consumer welfare and manufacturer profit via government subsidy programs: subsidizing consumers or manufacturers?" Manufacturing \& Service Operations Management, vol. 20, no. 4, pp. 752-766, 2018.

[8] S. Ji, D. Zhao, and R. Luo, "Evolutionary game analysis on local governments and manufacturers' behavioral strategies: impact of phasing out subsidies for new energy vehicles," Energy, vol. 189, Article ID 116064, 2019.

[9] S. Encarnação, F. P. Santos, F. C. Santos, V. Blass, J. M. Pacheco, and J. Portugali, "Paths to the adoption of electric vehicles: an evolutionary game theoretical approach," Transportation Research Part B: Methodological, vol. 113, pp. 24-33, 2018.

[10] Y. Yang, W. Yang, H. Chen, and Y. Li, "China's energy whistleblowing and energy supervision policy: an evolutionary game perspective," Energy, vol. 213, Article ID 118774, 2020.

[11] T.-H. Ho and S. Savin, "Managing demand and sales dynamics in new product diffusion under supply constraint," Management Science, vol. 48, no. 2, pp. 187-206.

[12] S. Kumar and J. M. Swaminathan, "Diffusion of innovations under supply constraints," Operations Research, vol. 51, no. 6 , pp. 866-879, 2003.

[13] B. Edelman, S. Jaffe, and S. D. Kominers, “To groupon or not to groupon: the profitability of deep discounts," Marketing Letters, vol. 27, no. 1, pp. 39-53, 2016.

[14] P. Y. Nie, X. Xiao, C. Wang, and T. Cui, "Innovation subsidy under duopoly," Managerial and Decision Economics, vol. 41, no. 3, pp. 362-370, 2020.

[15] X. Xiao, Z. R. Chen, and P. Y. Nie, "Analysis of two subsidies for EVs: based on an expanded theoretical discrete-choice model," Energy, vol. 208, Article ID 118375, 2020.

[16] S. Bansal and S. Gangopadhyay, "Tax/subsidy policies in the presence of environmentally aware consumers," Journal of Environmental Economics and Management, vol. 45, no. 2, pp. 333-355, 2003.

[17] J.-B. Sheu and Y. J. Chen, "Impact of government financial intervention on competition among green supply chains," International Journal of Production Economics, vol. 138, no. 1, pp. 201-213, 2012.

[18] M. C. Cohen, R. Lobel, and G. Perakis, "The impact of demand uncertainty on consumer subsidies for green technology adoption," Management Science, vol. 62, no. 5, pp. 1235-1258, 2016.

[19] J. Chemama, M. C. Cohen, R. Lobel, and G. Perakis, "Consumer subsidies with a strategic supplier: commitment vs. flexibility," Management Science, vol. 65, no. 2, pp. 681-713, 2019.

[20] Z.-r. Chen, X. Xiao, and P.-y. Nie, "Renewable energy hybrid subsidy combining input and output subsidies," Environmental Science and Pollution Research, vol. 28, no. 8, pp. 9157-9164, 2021.
[21] W. Gu, L. Wei, W. Zhang, and X. Yan, "Evolutionary game analysis of cooperation between natural resource- and energyintensive companies in reverse logistics operations," International Journal of Production Economics, vol. 218, pp. 159169, 2019.

[22] R. C. Lewontin, "Evolution and the theory of games," Journal of Theoretical Biology, vol. 1, no. 3, pp. 382-403, 1961.

[23] J. M. Smith, "Evolution and the theory of games," American Scientist, vol. 64, no. 1, pp. 41-45, 1976.

[24] P. D. Taylor and L. B. Jonker, "Evolutionary stable strategies and game dynamics," Mathematical Biosciences, vol. 40, no. 12, pp. 145-156, 1978.

[25] J. Cheng, B. Gong, and B. Li, "Cooperation strategy of technology licensing based on evolutionary game," Annals of Operations Research, vol. 268, no. 1, pp. 387-404, 2018.

[26] C. Homburg, A. Fürst, T. Ehrmann, and E. Scheinker, "Incumbents' defense strategies: a comparison of deterrence and shakeout strategy based on evolutionary game theory," Journal of the Academy of Marketing Science, vol. 41, no. 2, pp. 185-205, 2013.

[27] C. Gu, X. Wang, J. Zhao, R. Ding, and Q. He, "Evolutionary game dynamics of moran process with fuzzy payoffs and its application," Applied Mathematics and Computation, vol. 378, Article ID 125227, 2020.

[28] V. Mani, A. Gunasekaran, and C. Delgado, "Enhancing supply chain performance through supplier social sustainability: an emerging economy perspective," International Journal of Production Economics, vol. 195, pp. 259-272, 2018.

[29] D. Friedman, "Evolutionary economics goes mainstream: a review of the theory of learning in games," Journal of Evolutionary Economics, vol. 8, no. 4, pp. 423-432, 1998.

[30] C. Schmidt, "Are evolutionary games another way of thinking about game theory?" Journal of Evolutionary Economics, vol. 14, no. 2, pp. 249-262, 2004.

[31] H. P. Young, "Innovation diffusion in heterogeneous populations: contagion, social influence, and social learning," American Economic Review, vol. 99, no. 5, pp. 1899-1924, 2009.

[32] M. J. Lenox, S. F. Rockart, and A. Y. Lewin, "Interdependency, competition, and industry dynamics," Management Science, vol. 53, no. 4, pp. 599-615, 2007.

[33] D. W. Bunn and F. S. Oliveira, "Modeling the impact of market interventions on the strategic evolution of electricity markets," Operations Research, vol. 56, no. 5, pp. 1116-1130, 2008.

[34] J.-Y. Chen, S. Dimitrov, and H. Pun, "The impact of government subsidy on supply chains' sustainability innovation," Omega, vol. 86, pp. 42-58, 2019.

[35] L. Zhang, R. Long, Z. Huang, W. Li, and J. Wei, "Evolutionary game analysis on the implementation of subsidy policy for sustainable transportation development," Journal of Cleaner Production, vol. 267, Article ID 122159, 2020.

[36] R. Mahmoudi and M. Rasti-Barzoki, "Sustainable supply chains under government intervention with a real-world case study: an evolutionary game theoretic approach," Computers \& Industrial Engineering, vol. 116, pp. 130-143, 2018.

[37] H. Sun, Y. Wan, L. Zhang, and Z. Zhou, "Evolutionary game of the green investment in a two-echelon supply chain under a government subsidy mechanism," Journal of Cleaner Production, vol. 235, pp. 1315-1326, 2019.

[38] J. Li, H. Ren, C. Zhang, Q. Li, and K. Duan, "Substantive innovation or strategic innovation? Research on multiplayer stochastic evolutionary game model and simulation," Complexity, vol. 2020, Article ID 9640412, 15 pages, 2020. 
[39] L. Liu, Y. Zhu, and S. Guo, "The evolutionary game analysis of multiple stakeholders in the low-carbon agricultural innovation diffusion," Complexity, vol. 2020, Article ID 6309545, 12 pages, 2020.

[40] M. Li, S. P. Sethi, and J. Zhang, "Competing with bandit supply chains," Annals of Operations Research, vol. 240, no. 2, pp. 617-640, 2016.

[41] C. Arguedas and H. Hamoudi, "Controlling pollution with relaxed regulations," Journal of Regulatory Economics, vol. 26, no. 1, p. 96, 2004.

[42] A. B. da Silva Rocha and G. M. Salomão, "Environmental policy regulation and corporate compliance in evolutionary game models with well-mixed and structured populations," European Journal of Operational Research, vol. 279, no. 2, pp. 486-501, 2019.

[43] A. Atasu, L. N. Van Wassenhove, and M. Sarvary, "Efficient take-back legislation," Production and Operations Management, vol. 18, no. 3, pp. 243-258, 2009.

[44] G. Raz and A. Ovchinnikov, "Coordinating pricing and supply of public interest goods using government rebates and subsidies," IEEE Transactions on Engineering Management, vol. 62, no. 1, pp. 65-79, 2015.

[45] P. Xiao, R. Xiao, Y. Liang, X. Chen, and W. Lu, "The effects of a government's subsidy program: accessibility beyond affordability," Management Science, vol. 66, no. 7, pp. 32113233, 2020.

[46] R. Levi, G. Perakis, and G. Romero, "On the effectiveness of uniform subsidies in increasing market consumption," Management Science, vol. 63, no. 1, pp. 40-57, 2017.

[47] J. J. Yu, C. S. Tang, M. S. Sodhi, and J. Knuckles, "Optimal subsidies for development supply chains," Manufacturing \& Service Operations Management, vol. 22, no. 6, pp. 1131-1147, 2020.

[48] D. Friedman, "Evolutionary games in economics," Econometrica, vol. 59, no. 3, pp. 637-666, 1991.

[49] A. M. Lyapunov, The General Problem of the Stability of Motion, CRC Press, Boca Raton, FL, USA, 1992.

[50] J. Tanimoto, "Evolutionary Games with Sociophysics: Analysis of Traffic Flow and Epidemics," vol. 17, Springer, Berlin, Germany, 2019. 